\title{
Electromagnetic Power Attenuation in Soils
}

John O. Curtis

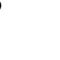




\section{Electromagnetic Power Attenuation in Soils}

John O. Curtis

Environmental Laboratory

U.S. Army Engineer Research and Development Center

3909 Halls Ferry Road

Vicksburg, MS 39180-6199

Final report

Approved for public release; distribution is unlimited

Prepared for U.S. Army Corps of Engineers

Washington, DC 20314-1000 
ABSTRACT: This study explores the possibility of predicting the attenuation of electromagnetic energy in soils as a function of soil type, soil moisture content, and the frequency of the sensor system being used to probe the soils. Of primary concern is the issue of safety; one does not want to risk an explosion when using high-power electromagnetic sensors to search for buried unexploded ordnance. While explicit predictive models could not be found because of the unpredictable effects of soil chemistry, simple statistical analyses did provide conservative guidance at fixed frequencies and selected soil moisture contents.

DISCLAIMER: The contents of this report are not to be used for advertising, publication, or promotional purposes. Citation of trade names does not constitute an official endorsement or approval of the use of such commercial products. All product names and trademarks cited are the property of their respective owners. The findings of this report are not to be construed as an official Department of the Army position unless so designated by other authorized documents. 


\section{Contents}

Preface

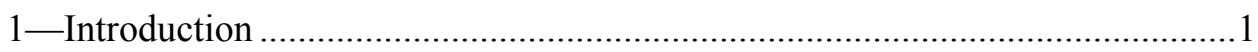

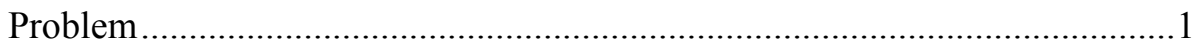

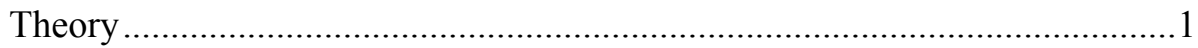

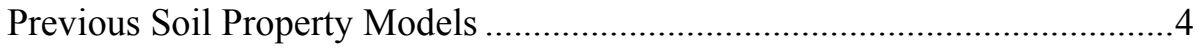

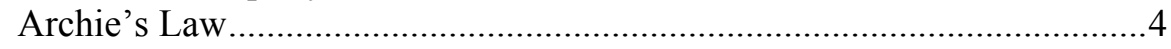

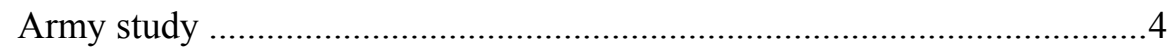

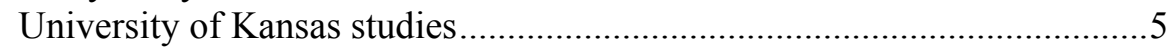

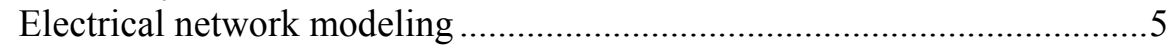

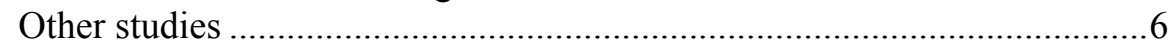

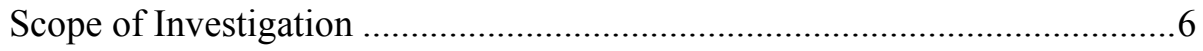

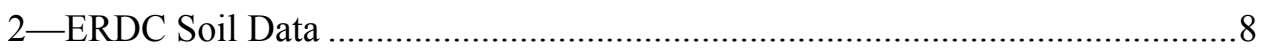

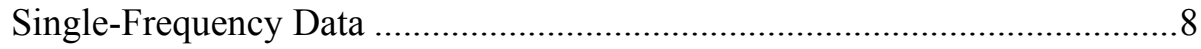

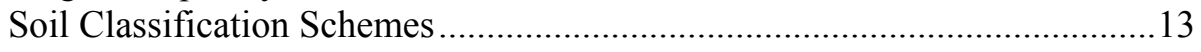

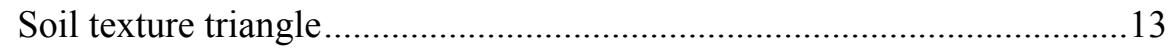

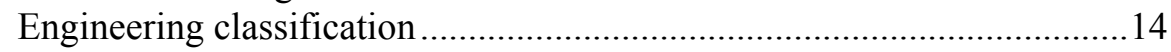

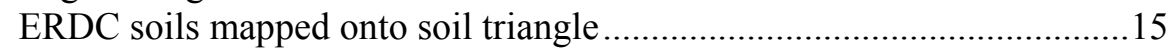

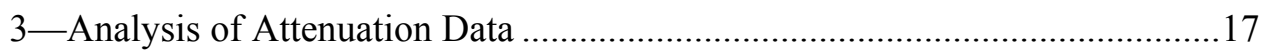

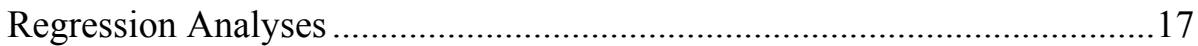

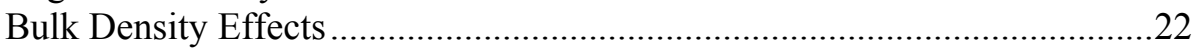

Temperature Effects ..........................................................................22

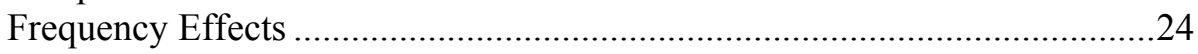

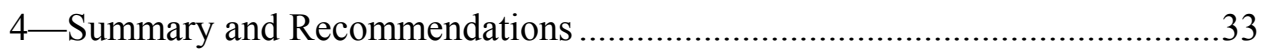

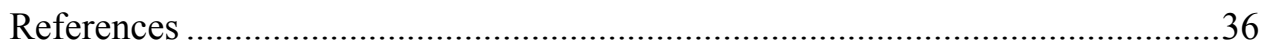

Appendix A: Soil Dielectric Property Data Collection and

Analysis Procedures ......................................................................A1

Complex Dielectric Property Measurements ..........................................A1

Calculation of Additional Parameters ...........................................................A2

SF 298 


\section{List of Figures}

Figure 1. Theoretical power attenuation for a conductivity of $10 \mathrm{mS} / \mathrm{m}$..........3

Figure 2. Theoretical power attenuation for a conductivity of $50 \mathrm{mS} / \mathrm{m}$..........3

Figure 3. Real (dielectric constant) vs. volumetric moisture content, $100 \mathrm{MHz}, 20 \mathrm{deg} \mathrm{C}$

Figure 4. Imaginary (dielectric constant) vs. volumetric moisture content, $100 \mathrm{MHz}, 20 \mathrm{deg} \mathrm{C}$.

Figure 5. Loss tangent vs. volumetric moisture content, $100 \mathrm{MHz}$, $20 \operatorname{deg} \mathrm{C}$

Figure 6. Apparent conductivity vs. volumetric moisture content, $100 \mathrm{MHz}, 20 \operatorname{deg} \mathrm{C}$

Figure 7. EM power attenuation vs. volumetric moisture content, $100 \mathrm{MHz}, 20 \operatorname{deg} \mathrm{C}$

Figure 8. Normalized phase velocity vs. volumetric moisture content, $100 \mathrm{MHz}, 20 \operatorname{deg} \mathrm{C}$ .12

Figure 9. U.S. Department of Agriculture soil texture triangle

Figure 10. Mapping of USCS classifications onto the USDA soil triangle ......16

Figure 11. EM power attenuation vs. volumetric moisture at $100 \mathrm{MHz}$ for USDA classifications.

Figure 12. EM power attenuation vs. volumetric moisture at $1,000 \mathrm{MHz}$ for USDA classifications.

Figure 13. EM power attenuation vs. volumetric moisture

at $100 \mathrm{MHz}$ for USCS classifications

Figure 14. EM power attenuation vs. volumetric moisture at $1,000 \mathrm{MHz}$ for USCS classifications.

Figure 15. Bulk density effects on EM power attenuation at $100 \mathrm{MHz}$ and $20 \mathrm{deg} \mathrm{C}$

Figure 16. Bulk density effects on EM power attenuation at $1,000 \mathrm{MHz}$ and $20 \mathrm{deg} \mathrm{C}$ .23

Figure 17. Temperature effects on EM power attenuation at $100 \mathrm{MHz}$ and $20 \mathrm{deg} \mathrm{C}$. 
Figure 18. Temperature effects on EM power attenuation at $1,000 \mathrm{MHz}$ and $20 \mathrm{deg} \mathrm{C}$

Figure 19a. EM power attenuation vs. volumetric moisture at $10 \mathrm{MHz}$ and $20 \mathrm{deg} \mathrm{C}$

Figure 19b. EM power attenuation vs. volumetric moisture at $10 \mathrm{MHz}$ and $20 \mathrm{deg} \mathrm{C}(\log$ scale) .26

Figure 20a. EM power attenuation vs. volumetric moisture at $100 \mathrm{MHz}$ and $20 \mathrm{deg} \mathrm{C}$

Figure 20b. EM power attenuation vs. volumetric moisture at $100 \mathrm{MHz}$ and $20 \mathrm{deg} \mathrm{C}$ (log scale)

Figure 21a. EM power attenuation vs. volumetric moisture at $500 \mathrm{MHz}$ and $20 \mathrm{deg} \mathrm{C}$ .28

Figure 21b. EM power attenuation vs. volumetric moisture at $500 \mathrm{MHz}$ and $20 \mathrm{deg} \mathrm{C}$ (log scale) .28

Figure 22a. EM power attenuation vs. volumetric moisture at $1,000 \mathrm{MHz}$ and $20 \mathrm{deg} \mathrm{C}$

Figure 22b. EM power attenuation vs. volumetric moisture at $1,000 \mathrm{MHz}$ and $20 \mathrm{deg} \mathrm{C}$ (log scale)

Figure 23a. EM power attenuation vs. volumetric moisture at 5,000 $\mathrm{MHz}$ and $20 \mathrm{deg} \mathrm{C}$

Figure $23 \mathrm{~b}$. EM power attenuation vs. volumetric moisture at 5,000 $\mathrm{MHz}$ and $20 \mathrm{deg} \mathrm{C}(\log$ scale $)$.... .30

Figure 24a. EM power attenuation vs. volumetric moisture at $10,000 \mathrm{MHz}$ and $20 \mathrm{deg} \mathrm{C}$

Figure 24b. EM power attenuation vs. volumetric moisture at $10,000 \mathrm{MHz}$ and $20 \mathrm{deg} \mathrm{C}(\log$ scale) 


\section{Preface}

This report was prepared in support of the FY03 UXO Support Program managed by the National Defense Center for Environmental Excellence. Within that program, Task 307, Subtask 7, entitled "Active EMI Effects on Electronic Fuses," was executed by Concurrent Technologies Corporation, in North Charleston, SC, under the lead of Dr. George Pusey. The study reported herein is part of Work Unit 7.3, which was executed by Mr. Larry Overbay at the Aberdeen Test Center, Aberdeen Proving Ground, MD. The Technical Program Monitor for Subtask 7 was Mr. George Robitaille from the Army Environmental Center, Aberdeen Proving Ground, MD.

Dr. John O. Curtis, Environmental Systems Branch (ESB), Ecosystem Evaluation and Engineering Division (EE), Environmental Laboratory (EL), Engineer Research and Development Center (ERDC), Vicksburg, MS, conducted this study with statistical analysis assistance provided by Ms. Tere DeMoss, ESB. This investigation was conducted under the direct supervision of Dr. Rose Kress, Chief, ESB, and the general supervision of Dr. Dave Tazik, Chief, EE.

At the time of publication of this report, Dr. Edwin A. Theriot was Director, EL, and Dr. James R. Houston was Director of ERDC. Commander and Executive Director of ERDC was COL James R. Rowan, EN. 


\section{Introduction}

\section{Problem}

This study investigates the suitability of simple mathematical models for predicting the attenuation of electromagnetic (EM) energy in soils. The motivation for this effort is a safety issue. Explosives and ordnance (EOD) cleanup crews may need to utilize electromagnetic sensors to detect and identify unexploded ordnance (UXO) buried in various types of soils. They must be reasonably certain that their instruments will not trigger a premature detonation of the UXO.

Experience has shown (see discussion in the next section) that EM power attenuation in soils is a strong function of the frequency of the waves, the amount of moisture in the soil, and the type of soil (soil chemistry). Soil density and soil temperature are less important factors. Therefore, the goal of this effort was to generate mathematical models to predict EM attenuation as a function of soil type, soil moisture, and frequency of the sensor system. If EOD crews (or scientists and engineers who are testing new equipment) are able to classify field site soils as well as estimate the volumetric moisture content of the soils, then the models pursued in this study can be utilized to estimate power attenuation in those soils and identify conditions under which the crews might face risks in working with the equipment.

\section{Theory}

A plane electromagnetic wave traveling through soil whose electrical behavior can be characterized by a frequency-dependent complex dielectric permittivity will experience a loss of power that can be calculated by the following formula (see Appendix A):

$$
\text { power } \operatorname{loss}\left(\frac{d B}{m}\right)=-8.6859 \frac{\omega}{c}\left[\frac{\varepsilon^{\prime}}{2}\left(\sqrt{1+\left(\frac{\varepsilon^{\prime \prime}}{\varepsilon^{\prime}}\right)^{2}}-1\right)\right]^{\frac{1}{2}}
$$


where

$$
\begin{aligned}
\varepsilon^{\prime}, \varepsilon^{\prime \prime}= & \text { real and imaginary parts of the relative complex dielectric } \\
& \text { permittivity, respectively } \\
\omega= & \text { angular frequency of the wave }(=2 \pi f, f \text { is the frequency in cycles } \\
& \text { per second, or Hz }) \\
c= & \text { speed of light }\left(3 \times 10^{8} \mathrm{~m} / \mathrm{s}\right) .
\end{aligned}
$$

The ratio of the imaginary part of the dielectric permittivity to the real part is often referred to as the loss tangent.

If, instead of characterizing a soil by its complex dielectric permittivity, it is described by a real dielectric permittivity and an electrical conductivity, then Equation 1 could be written as:

$$
\text { power loss }=-8.6859 \frac{\omega}{c}\left[\frac{\varepsilon^{\prime}}{2}\left(\sqrt{1+\left(\frac{\sigma}{\varepsilon^{\prime} \varepsilon_{0} \omega}\right)^{2}}-1\right)\right]^{\frac{1}{2}}
$$

where

$$
\begin{aligned}
\sigma & =\text { electrical conductivity }(\mathrm{mho} / \mathrm{m} \text {, or seimens } / \mathrm{m}) \\
\varepsilon_{0} & =\text { electrical permittivity of free space }\left(8.85 \times 10^{-12} \text { farads } / \mathrm{m}\right)
\end{aligned}
$$

Equation 2 can be used to generate power attenuation predictions for given values of the dielectric constant and electrical conductivity. The results are shown in Figures 1 and 2 on the following pages. In Figure 1, power attenuation has been plotted against operating frequency for a conductivity value of 10 milliSiemens per meter $(\mathrm{mS} / \mathrm{m})$, which is typical of low conductivity soils, and various values of the dielectric constant. Figure 2 is the same chart for a conductivity value of $50 \mathrm{mS} / \mathrm{m}$, which could be representative of high conductivity soils. These charts can only be used if one knows the values of dielectric constant and electrical conductivity. The problem is that the electrical properties of soils are a function of frequency, moisture content of the soil, the chemistry of the soil that determines how many ions can be produced when moisture levels change, the temperature of the soil/water/air matrix, and, in some very complex manner, the structure of the matrix, which is related to its dry density, its porosity, and the type of minerals it contains.

Another interesting point to make from the theoretical predictions shown in Figures 1 and 2 is that, contrary to intuitive understanding, electrical conductivity alone does not control EM power loss in soils. Clearly, all other things being equal, power attenuation increases with increasing conductivity. However, as these figures show, at some frequencies, a low dielectric permittivity, low conductivity soil can experience as much power attenuation as a high permittivity, high conductivity soil. While it may seem far-fetched, a possible 


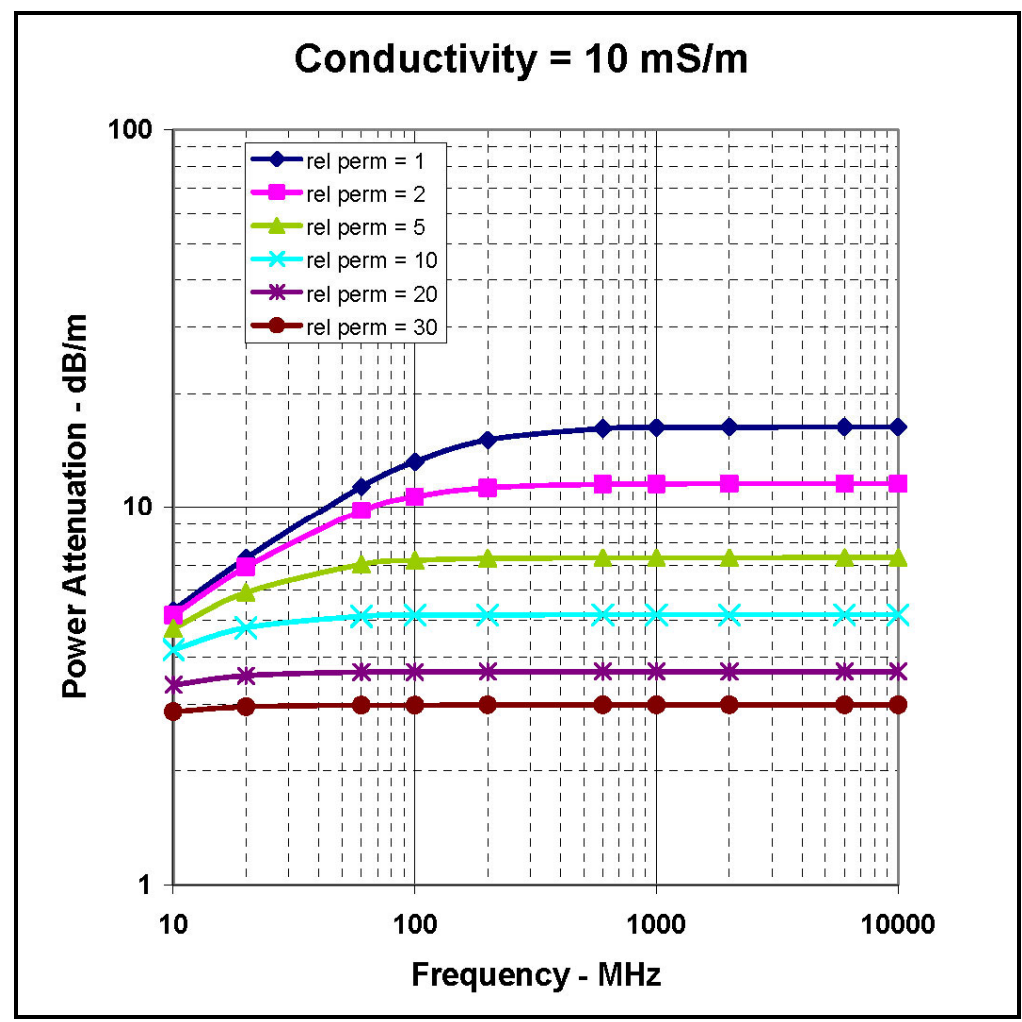

Figure 1. Theoretical power attenuation for a conductivity of $10 \mathrm{mS} / \mathrm{m}$

Figure 2. Theoretical power attenuation for a conductivity of $50 \mathrm{mS} / \mathrm{m}$

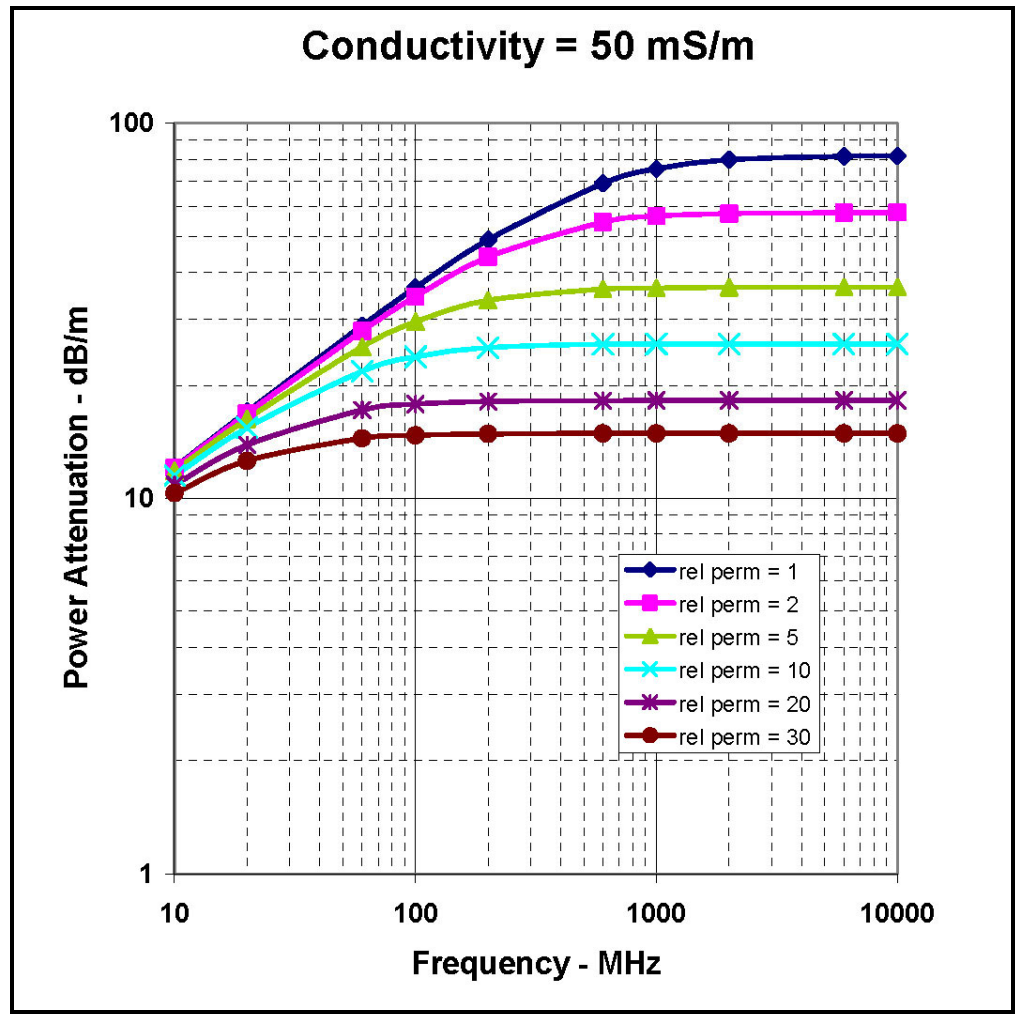


explanation is that the low permittivity soil allows the charged particles more opportunity to be exposed to electrical loss mechanisms (by not allowing them to be trapped as stored energy), thus effectively producing more electrical loss.

What this means is that one must be very cautious in utilizing "rules-of-thumb" for power attenuation in soils based on field measurements of effective conductivity.

\section{Previous Soil Property Models}

Clearly, the problem of predicting EM attenuation in soils reduces to predicting the electrical properties of the soils, whether they be expressed as a complex dielectric permittivity or a real, relative dielectric permittivity and an electrical conductivity. The literature is replete with attempts to model soil electrical properties as functions of other soil parameters such as moisture content, soil texture, and resistivity of pore water, etc. Unfortunately, at best, these models are site specific, and one cannot avoid scooping up samples in the field that must be analyzed in a laboratory.

\section{Archie's Law}

As an example, consider Archie's Law (Archie 1942) for calculating the effective electrical resistivity of a soil:

$$
\rho_{e}=a \varphi^{-m} s^{-n} \rho_{w}
$$

where

$$
\begin{aligned}
\varphi & =\text { the fractional pore volume (porosity) } \\
s & =\text { the fraction of pores containing water } \\
\rho_{w} & =\text { the resistivity of the pore water }
\end{aligned}
$$

$a, n$, and $m=$ constants

This formula gives the soil conductivity (the inverse of the resistivity), but only after conducting laboratory measurements of soil porosity and pore water resistivity and doing whatever is necessary to estimate the other parameters. Clearly, direct measurements of soil attenuation in a laboratory are simpler.

\section{Army study}

Another early model of soil conductivity came from an extensive field measurement program conducted by the U.S. Army (Hulse et al. 1972). An equation for conductivity, $\sigma$, was developed for regional soils:

$$
\sigma=1+8.4(m: k)^{2.3}-0.1 c
$$


where

$$
\begin{aligned}
c= & \text { the clastic fraction by percent weight (assumed to represent the } \\
& \text { fraction of soil containing mineral and rock fragments) } \\
m: k= & \text { weight ratio of montmorillonite to kaolinite clays in the soil. }
\end{aligned}
$$

Using this model requires extensive soil chemistry experiments to determine clay mineral ratios, as well as whatever techniques are needed to estimate the clastic fraction.

\section{University of Kansas studies}

Possibly recognizing that such models are too esoteric for many field engineers and scientists, a group at the University of Kansas, and later at the University of Michigan, attempted to model soil electrical properties as a function of soil physical properties (Hallikainen et al. 1985). The following formulae were proposed for values of the complex dielectric constant:

$$
\begin{aligned}
& \varepsilon^{\prime}=\left(a_{0}^{\prime}+a_{1}^{\prime} S+a_{2}^{\prime} C\right)+\left(b_{0}^{\prime}+b_{1}^{\prime} S+b_{2}^{\prime} C\right) m_{v}+\left(c_{0}^{\prime}+c_{1}^{\prime} S+c_{2}^{\prime} C\right) m_{v}^{2} \\
& \varepsilon^{\prime \prime}=\left(a_{0}^{\prime \prime}+a_{1}^{\prime \prime} S+a_{2}^{\prime \prime} C\right)+\left(b_{0}^{\prime \prime}+b_{1}^{\prime \prime} S+b_{2}^{\prime \prime} C\right) m_{v}+\left(c_{0}^{\prime \prime}+c_{1}^{\prime \prime} S+c_{2}^{\prime \prime} C\right) m_{v}^{2}
\end{aligned}
$$

where

$$
\begin{aligned}
S= & \text { the weight fraction of sand particles in the soil (diameter between } \\
& 0.05 \mathrm{~mm} \text { and } 2.0 \mathrm{~mm}) \\
C= & \text { the weight fraction of clay particles in the soil (diameter less than } \\
& 0.002 \mathrm{~mm}) \\
m_{v}= & \text { the volumetric moisture content of the soil }
\end{aligned}
$$

and the coefficients are determined by fitting laboratory data collected over the range of frequencies being studied. Each frequency has associated with it a different set of coefficients.

These equations are exactly what is desired for this study: select an operating frequency; make a site measurement of moisture content; perform a simple onsite soil classification to determine sand and clay fractions; and calculate the complex dielectric constant. From Equation 1, one can then predict EM attenuation. Unfortunately, the coefficients are soil-dependent. In fact, it is highly probable that two soils with similar texture and moisture values will produce vastly different dielectric constant values because of differing chemistries.

\section{Electrical network modeling}

Another approach to modeling soil electrical properties that accounts for their dispersive (frequency-dependent) nature is that of using electrical networks 
of resistors and capacitors whose parameters are chosen to fit specific laboratory data (Smith and Arulanandan 1981). For example, the apparent conductivity of the soil can be modeled:

$$
\sigma_{t h}=\frac{a}{d(1-d) S}\left[\frac{k_{r} k_{s}^{2}}{1-d}+\frac{k_{r}^{2} k_{s}}{d}+\omega^{2} \varepsilon_{v}^{2}\left(\frac{\varepsilon_{s}^{2} k_{r}}{1-d}+\frac{\varepsilon_{r}^{2} k_{s}}{d}\right)\right]+b k_{r}+c k_{s}
$$

in which

$$
S=\left(\frac{k_{s}}{1-d}+\frac{k_{r}}{d}\right)^{2}+\omega^{2} \varepsilon_{v}^{2}\left(\frac{\varepsilon_{d}}{1-d}+\frac{\varepsilon_{r}}{d}\right)^{2}
$$

$a, b, c$, and $d$ are geometrical weighting parameters associated with electrical path lengths through a soil sample and relative amounts of soil solids and soil solutions, while $\varepsilon_{r}$ and $k_{r}$ are the relative dielectric constant and electrical conductivity of the soil fraction, and $\varepsilon_{s}$ and $k_{s}$ are the relative dielectric constant and electrical conductivity of the soil solution.

Once again, a model such as Equation 7 is not an improvement over simply making permittivity and conductivity measurements directly. The weighting parameters are found from real conductivity data, anyway. Furthermore, every different soil has a different set of weighting parameters.

\section{Other studies}

There are many other references in the literature to soil electrical property measurements and modeling (Hipp 1974; Hoekstra and Delaney 1974; Campbell 1990; Marinelli et al. 1999; Miller et al. 2002; Cooke and Gladwin 2004). As with those above, they all fall short of the requirements for this study in that none of them provide a universal model for all soils, or even broad classes of soils. The earlier studies always dealt with, at most, a few different soil samples.

\section{Scope of Investigation}

The hope for this investigation was that a statistical analysis of a large amount of frequency-dependent laboratory data on soils of varying texture, moisture content, bulk density, and possibly temperature might result in an acceptable model for predicting EM attenuation from simple measurements that can be conducted easily in the field. The chapters that follow document this effort.

Chapter 2 begins with a brief description of how electrical property data have been collected at ERDC and goes on to display those data at a single frequency and a single temperature. The two soil classification schemes used in this effort are also briefly discussed. The chapter concludes with a visual representation of both soil classifications. 
Chapter 3 steps through the analysis of the attenuation data at each of five selected frequencies. Arguments are made for whether or not each of the soil physical properties play a significant role in predicting EM attenuation.

Conclusions are summarized in Chapter 4, and recommendations are made as to how to provide a factor of safety to equipment users in the field.

An appendix is provided that includes the development of the theoretical relationships among the electrical properties and various physical properties of the soils that were tested at ERDC. 


\section{ERDC Soil Data}

Since about 1990, the author has measured the complex dielectric constant of hundreds of soil samples. Many of these samples were taken from military installations in the United States as well as from locations in Europe and the Middle East. A number of samples of "prepared" soils from the U.S. Army Corps of Engineers Geotechnical Laboratory in Vicksburg, MS, as well as several benchmark soils from the National Soils Survey Center in Lincoln, NE, were also studied.

Fine-grained materials were packed into coaxial sample holders whose temperature could be controlled. Normally, the sample holders were packed with the soil as it was drawn from the container in which it was shipped, and a measurement of the complex dielectric properties of that sample were made over a selected band of frequencies. If the soil was noticeably damp, it might be airdried while still in the container, after which its properties were measured again. Finally, distilled, deionized water might be added, and the sample allowed to reach an equilibrium condition before another measurement was made. In summary, each physical sample would be interrogated at at least three different moisture contents (Curtis 2001b).

While each measurement set covered different specific frequency limits, most of the data cover overlapping frequency bands. For this reason, and given the measurement technique described above, the author believes these measurements represent a statistically significant data set whose independent variables include soil type, frequency, volumetric moisture, soil bulk density, and, to a lesser extent, soil sample temperature. In this study it was hoped that such a data set would be a viable source of EM attenuation prediction models.

\section{Single-Frequency Data}

As an example of data collected since 1990, the following charts contain soil electrical property data plotted against volumetric moisture content at one frequency, $100 \mathrm{MHz}$, and at one temperature, $20 \mathrm{deg} \mathrm{C}$. There are approximately 1,080 data points on each chart, representing between 300 and 400 distinct soil samples. It is also important to note that these scatter plots distinguish neither soil classifications nor soil bulk density. Therefore, the only variable on this first 
set of charts is volumetric moisture content. The next chapter will contain a study of attenuation data as a function of the other test and soil parameters.

Laboratory data are first processed to produce frequency-dependent values of the complex dielectric constant using the algorithm described in Appendix A. Other electrical parameters are then calculated from the complex dielectric constant values using equations that are also found in Appendix A.

Figures 3 and 4 contain the real and imaginary parts of the complex dielectric constant, respectively. Clearly, there is a very strong relationship between the real part of the complex dielectric constant (which is also referred to as the dielectric permittivity) and volumetric moisture content. Other than a few "outlier" data points, one could readily accept a model fit to these data by regression that would pass through the center of the narrow band of data. In fact, this is exactly what is done with some field equipment used to measure soil moisture. If one is willing to accept the spread of data in Figure 3 as the error bar, then a model can be easily generated that predicts soil moisture from a measurement of the dielectric permittivity (Topp et al. 1980; Curtis 2001a). A value of the permittivity can be obtained from a field instrument that treats the soil at the end of the open-ended coaxial probe as a shunt capacitance.

The five outlier data points on Figure 3 that fall above the band of concentrated data all come from measurements on a manufactured soil that was a mix of clean sand and magnetite. It is entirely possible that the high values of dielectric permittivity are a product of the assumption used in data processing that the soil is nonmagnetic. One of the four outlier data points that fall below the concentration band is from a soil that is a natural magnetic mineral bearing soil. The chemistry of the other three points is unknown other than two of them visually classified (Unified Soil Classification System) as an organic silty sand from Alaska, and the other is a soil sample taken from a 2-meter depth at the Aberdeen Proving Ground, MD. In fact, these low-value outliers may represent nothing more than a computational/experimental error.

While a strong relationship exists between dielectric permittivity and volumetric moisture content, virtually no relationship exists between the parameters that reflect energy losses in the soil and moisture content. For example, the imaginary component of the complex dielectric constant (Figure 4) plotted against volumetric moisture produces a true "scatter" plot. Both the loss tangent and the apparent conductivity (Figures 5 and 6, respectively) produce similar results.

Although power attenuation and phase velocity (Equations A16 and A17, respectively) are functions of both the real and imaginary parts of the complex dielectric constant, Figure 7 shows that power attenuation cannot be predicted by moisture content alone. On the other hand, Figure 8 reveals that the phase velocity of EM waves traveling through all of the soils tested at ERDC is highly correlated with volumetric moisture content. This latter observation is supported, in part, by noting that for the majority of loss tangent values measured at ERDC, the phase velocity will be inversely proportional to the square root of the 
Figure 3. Real (dielectric constant) vs. volumetric moisture content, $100 \mathrm{MHz}, 20 \operatorname{deg} \mathrm{C}$

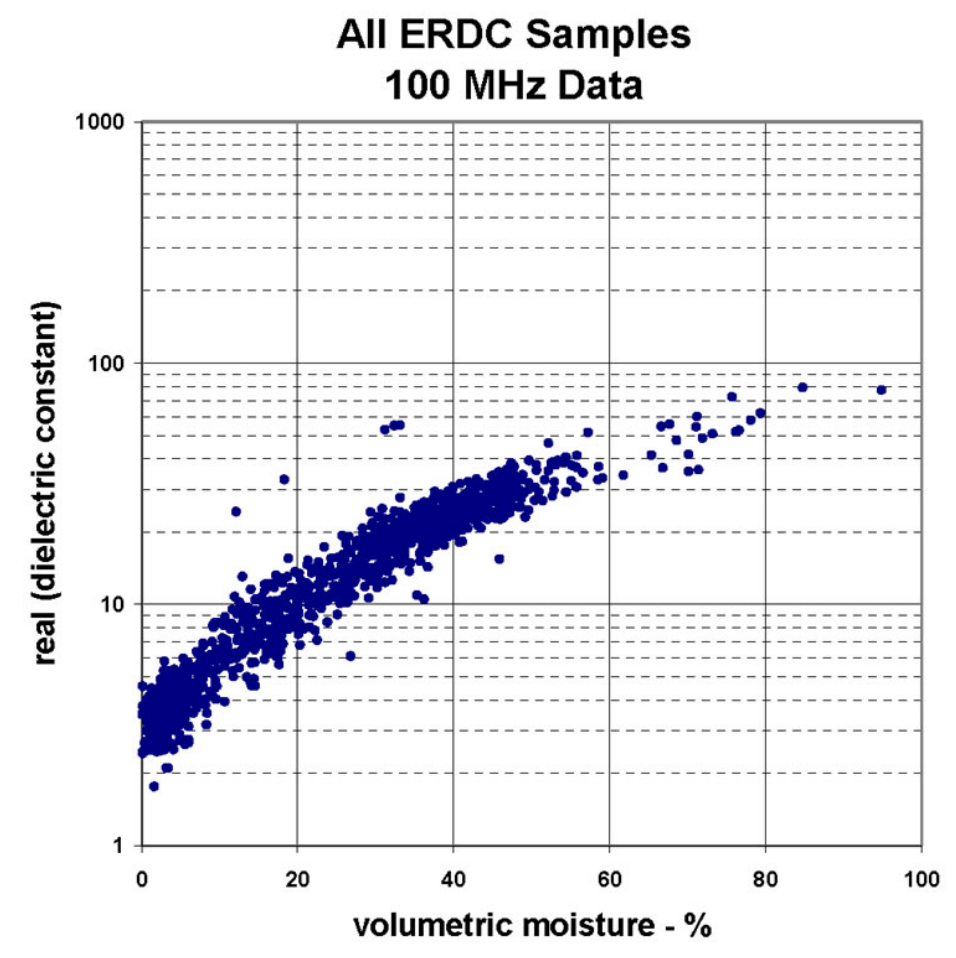

All ERDC Samples

Figure 4. Imaginary (dielectric constant) vs. volumetric moisture content, $100 \mathrm{MHz}, 20 \operatorname{deg} \mathrm{C}$ 
Figure 5. Loss tangent vs. volumetric moisture content, $100 \mathrm{MHz}$, $20 \operatorname{deg} \mathrm{C}$
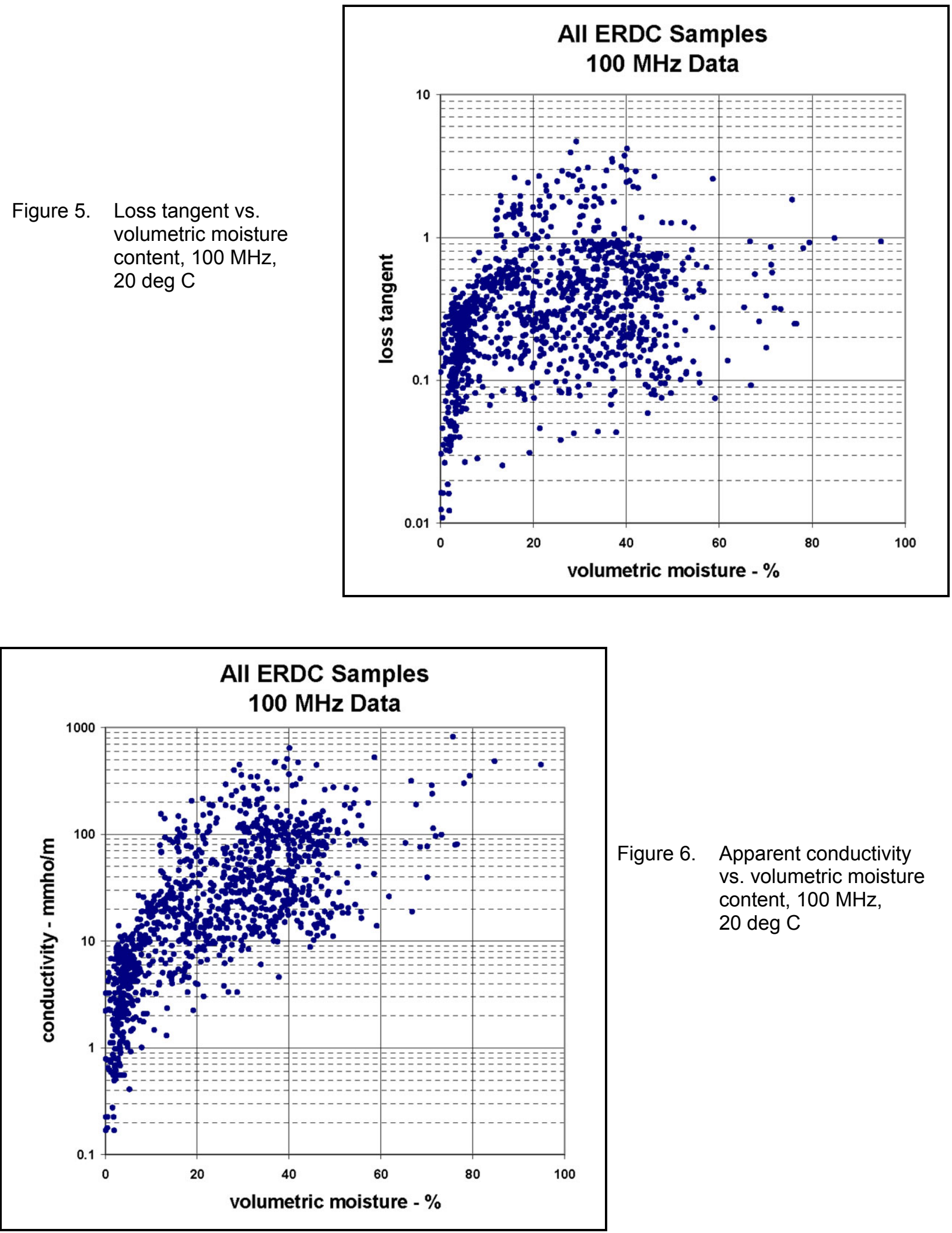

Figure 6. Apparent conductivity vs. volumetric moisture content, $100 \mathrm{MHz}$, $20 \operatorname{deg} \mathrm{C}$ 
Figure 7. EM power attenuation vs. volumetric moisture content, $100 \mathrm{MHz}$, $20 \operatorname{deg} \mathrm{C}$
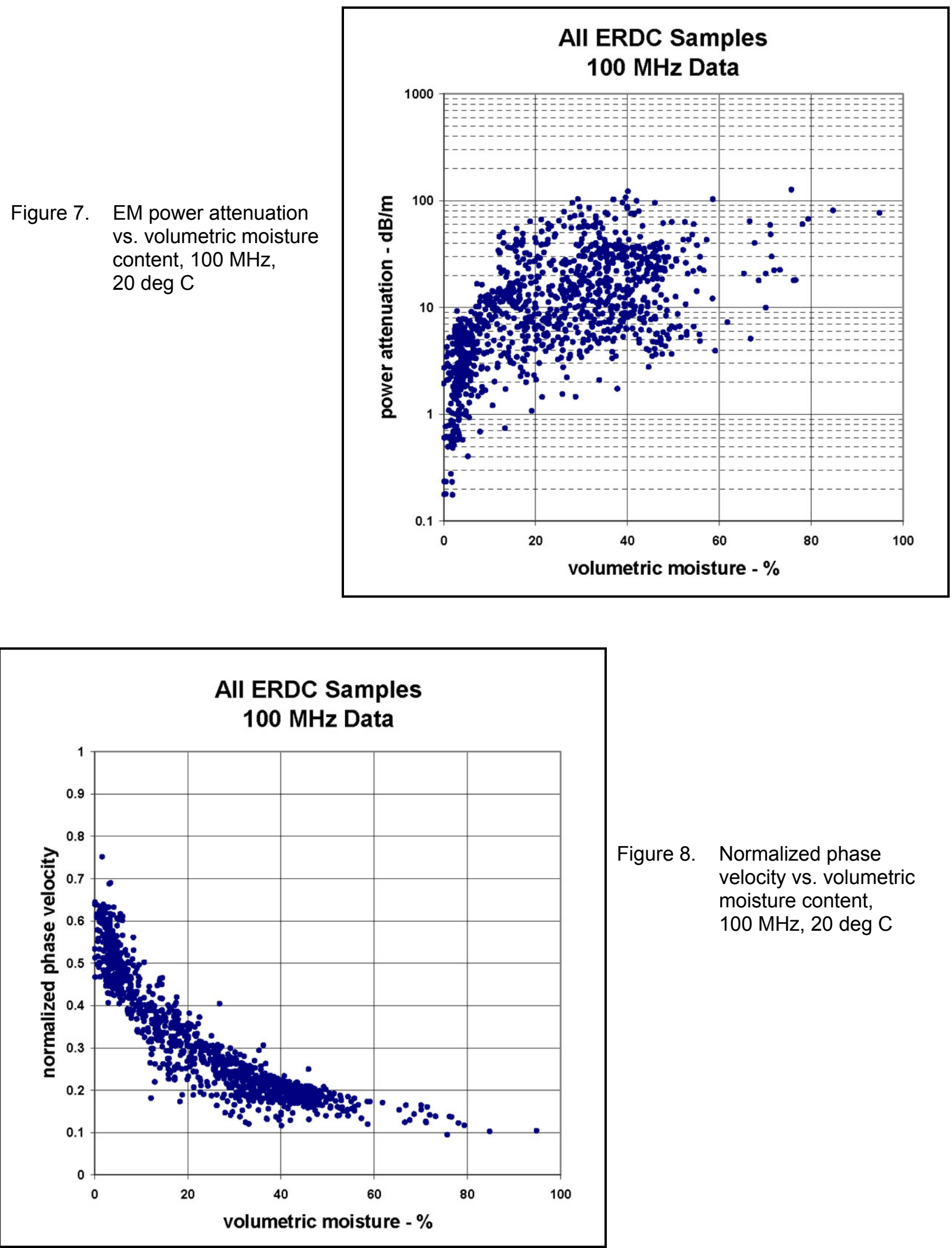

Figure 8. Normalized phase velocity vs. volumetric moisture content, $100 \mathrm{MHz}, 20 \operatorname{deg} \mathrm{C}$ 
dielectric permittivity. Since permittivity is highly correlated with moisture content, then it should be no surprise that phase velocity is also highly correlated.

In summary, single-frequency soil electrical property data $(100 \mathrm{MHz})$ show that dielectric permittivity and phase velocity are strong functions of soil volumetric moisture content. All other data, including EM power attenuation, are not strongly correlated with moisture content. Further analyses in Chapter 3 will focus on other properties of the soils, including measurement frequency, soil texture, bulk density, and physical temperature, in an effort to produce models that can predict soil EM attenuation from relatively simple field measurable parameters.

\section{Soil Classification Schemes}

The goal of this study is to derive EM attenuation prediction models for soils using the least number of parameters possible that can be easily obtained by an experienced soil scientist or soils engineer working in the field. It is believed that one of those parameters would be a soil type classification label. Two different soil classification systems were used in this study to label as many of the ERDC-tested soil samples as possible. One of them came from the agricultural community, and the other grew out of the need to label the engineering properties of soils.

\section{Soil texture triangle}

The U.S. Department of Agriculture (USDA) soil classification system is an adaptation of a late- $19^{\text {th }}$ century Russian system that permitted the study of soils with the same agricultural characteristics (Portland Cement Association 1973). In other words, agricultural experts desired a way to classify soils so that soils in various parts of the world that possessed the same drainage characteristics and that came from the same topography would grow the same kinds of crops when exposed to similar weather conditions. This classification scheme leads to labeling a soil with a great soil group name such as alluvial soils or laterite soils. The great soil group name reflects the soil maturity and the climate, vegetation, and topography of its location. Each group is further divided into series. All soils within a series are similar in all respects except the texture. Texture can be defined as the relative distribution of particles sizes within a soil sample. It is this final textural classification that was used to label the ERDC soil samples.

In graphical form, Figure 9 defines the 12 basic textural groups used by the USDA Natural Resources Conservation Service. To properly use this chart, one first needs to calculate the relative amounts of specified particle-size bands. Using only that portion of a soil that will pass through a No. 10 sieve $(2 \mathrm{~mm})$, a particle-size distribution curve can be generated in a laboratory. The portion called sand consists of particles between 0.05 and $2.0 \mathrm{~mm}$ in size; silt falls between 0.002 and $0.05 \mathrm{~mm}$; and clay consists of everything smaller than $0.002 \mathrm{~mm}$ in size. Each point on the textural triangle in Figure 9 represents a 
Figure 9. U.S. Department of Agriculture soil texture triangle

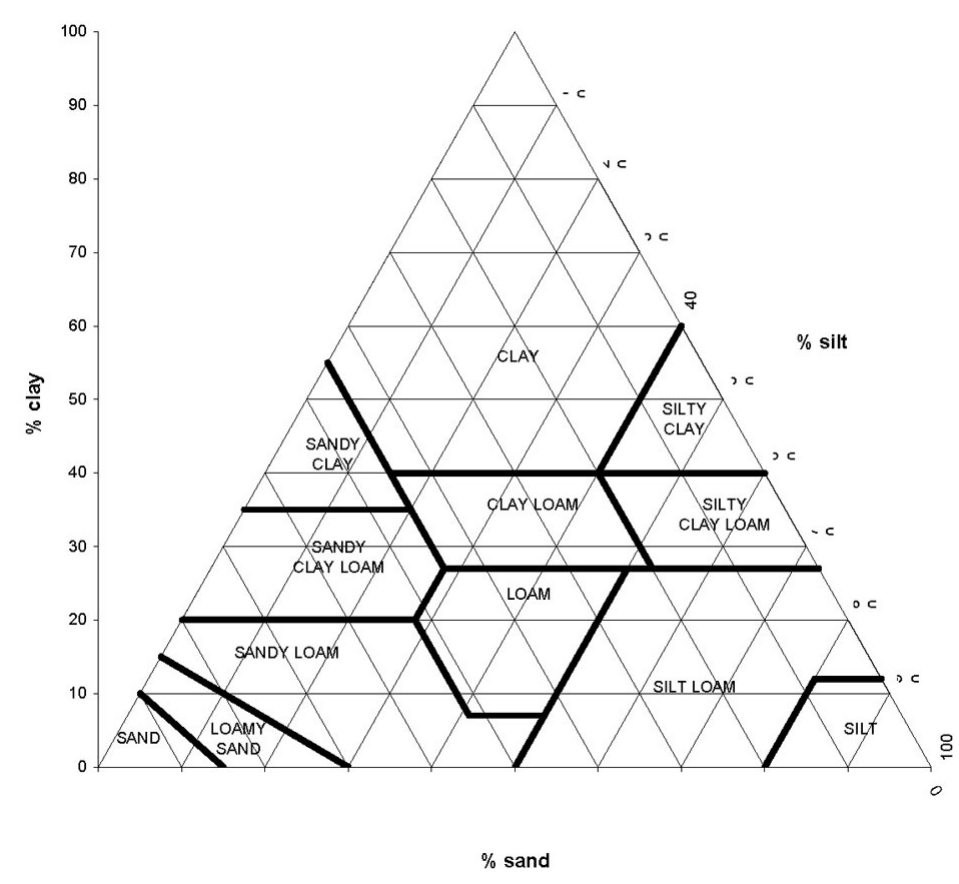

unique combination of sand and clay content. For a given textural class, all combinations of sand and clay content are bound by a polygon that bears the name of the class. For example, a soil possessing 30 percent sand and 35 percent clay-sized particles would be classified as a "clay loam."

\section{Engineering classification}

In 1942 the U.S. Army Corps of Engineers adopted the "Airfield Classification" system for soils that had been developed by Arthur Casagrande, a professor of civil engineering at Harvard University. With minor alterations it became what today is known as the Unified Soil Classification System (USCS). Its purpose was to classify soils in a way that would indicate how the soil would behave as an engineering construction material (U.S. Army Engineer Waterways Experiment Station 1960).

Like the USDA soil texture triangle, the USCS is based, in part, on the shape of the soil particle-size distribution curve. However, the USCS technique considers all sizes of material within the soil. Furthermore, it labels sands as having grain sizes between $0.074 \mathrm{~mm}$ (No. 200 sieve) and $4.76 \mathrm{~mm}$ (No. 4 sieve), while silts and clays are those particles smaller than $0.074 \mathrm{~mm}$. The USCS goes on to include in its classification procedure two other laboratorymeasured parameters called the liquid limit and the plastic limit (which are related by a term called the plasticity index), which are collectively known as the Atterberg limits. The liquid limit is the weight-based moisture content above which the soil flows as a viscous liquid, and below which it is plastic. The plastic limit is the moisture content at which the soil will start to crumble when 
rolled into a thread under the palm of the hand. The plasticity index is just the difference between the liquid limit and the plastic limit.

Classification by the USCS involves following a decision flowchart that combines key particle-size distribution curves values with the soil plasticity parameters defined above to arrive at one of 15 different classification labels. Each label has associated with it a word description of the soil. For example, an OL soil is described as "organic silts and organic silty clays of low plasticity." The USCS silt covers a different particle-size band than does its USDA counterpart.

USDA and USCS classification labels were applied to all of the ERDC soil samples for which such information was available. Of the 1,080 data samples shown on the first few charts, approximately 375 of those received USDA classification labels. Approximately 460 could be classified according to the USCS. These will constitute the data that are analyzed in the following chapter.

\section{ERDC soils mapped onto soil triangle}

An obvious question that needs to be answered is whether or not USDA and USCS classifications are comparable in some straightforward way. To answer this question, all of the soil samples tested at ERDC that could be classified by both methods as well as a few soils whose classifications were found in other reports were mapped onto the USDA soil texture triangle shown in Figure 10. If there was a strong correlation between the two classification schemes, then each USCS label would be concentrated in only one or two of the USDA triangle polygons. Clearly, this is not the case. One has to conclude that there is no simple way to transfer USDA classifications to the USCS and vice versa. Each scheme will need to be examined independently for its ability to produce an EM attenuation prediction model. 


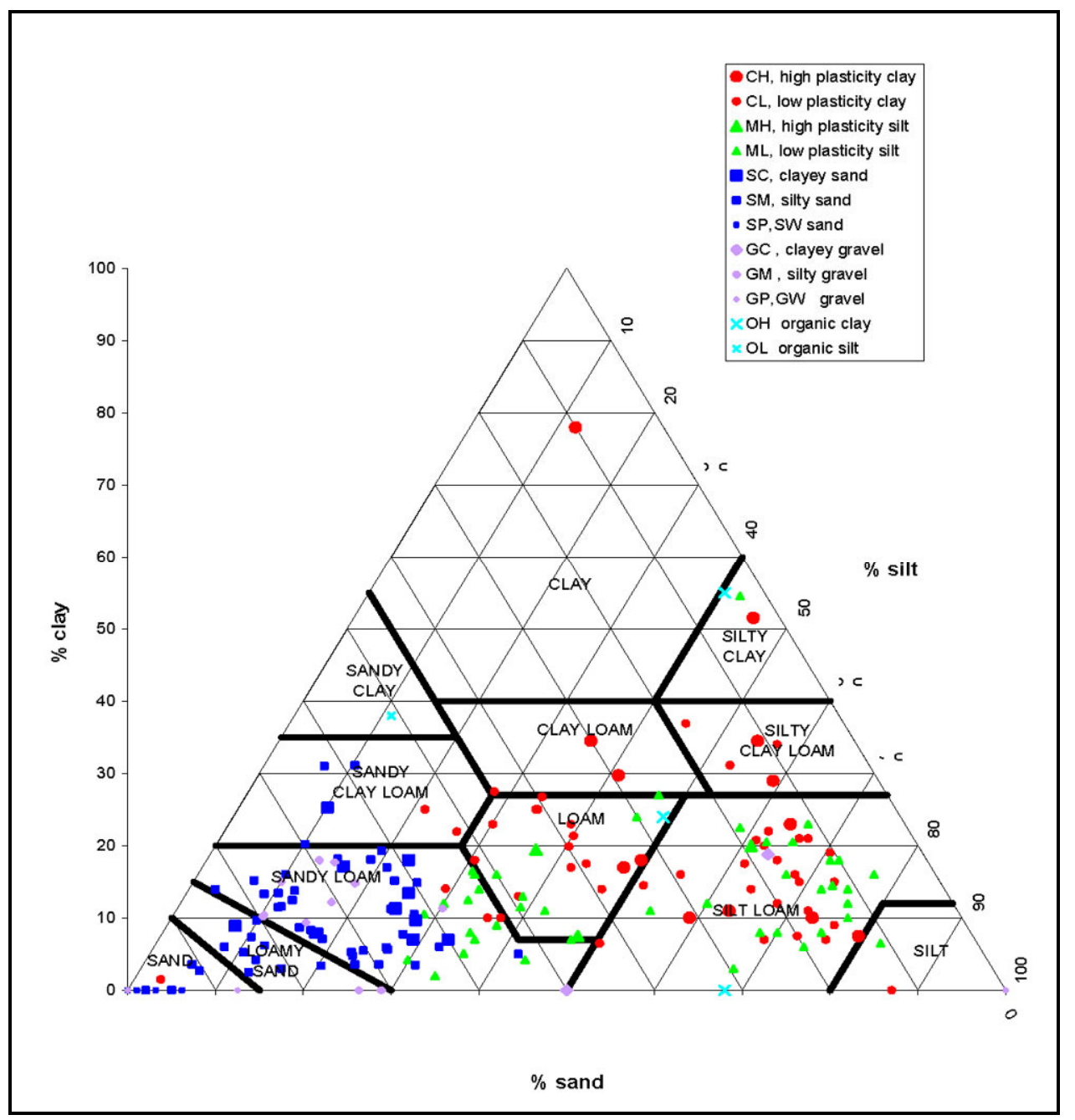

Figure 10. Mapping of USCS classifications onto the USDA soil triangle 


\section{Analysis of Attenuation Data}

\section{Regression Analyses}

As noted earlier, the ultimate goal of this study was to develop useful EM power attenuation prediction models whose input would consist of parameters easily measured in the field. If laboratory measurements were required to provide model input, then direct attenuation measurements in a laboratory could be made just as easily, and predictive models would not be necessary.

Analysis of the ERDC database began with blind linear regressions using SPSS 9.0, a comprehensive computer software package for analyzing data. EM power attenuation was taken to be the dependent variable, while the independent variables were chosen to be frequency, volumetric moisture content, and sample bulk density. One set of regressions were performed for the USDA soil classifications, and another set were performed for the USCS soil classifications. In some cases, SPSS could not produce a model; in others the fits were of very poor quality as evidenced in low $\mathrm{R}^{2}$ values $\left(\mathrm{R}^{2}\right.$ is an estimate of the variance of a model fit from actual data and is often referred to as the residual sum of squares or the error sum of squares).

It was quickly established that fits needed to be attempted at fixed values of frequency. Models were generated at frequencies of $10 \mathrm{MHz}, 100 \mathrm{MHz}, 500$ $\mathrm{MHz}, 1,000 \mathrm{MHz}, 5,000 \mathrm{MHz}$, and 10,000 MHz for each set of soil classifications. Once again, results were very poor. Showing tables of these results would be meaningless at this point in light of the arguments that are going to be made in the following sections.

Clear evidence of the failure to produce accurate predictive models can be seen in Figures 11-14. These are charts of EM power attenuation plotted against volumetric moisture content at fixed frequencies. The sample temperature was always $20 \mathrm{deg} \mathrm{C}$, and the data points represent the entire range of bulk densities measured at ERDC. Figures 11 and 12 are for USDA classifycations and for 100 $\mathrm{MHz}$ and 1,000 MHz, respectively. Figures 13 and 14 represent the same parameters but for USCS classifications. 


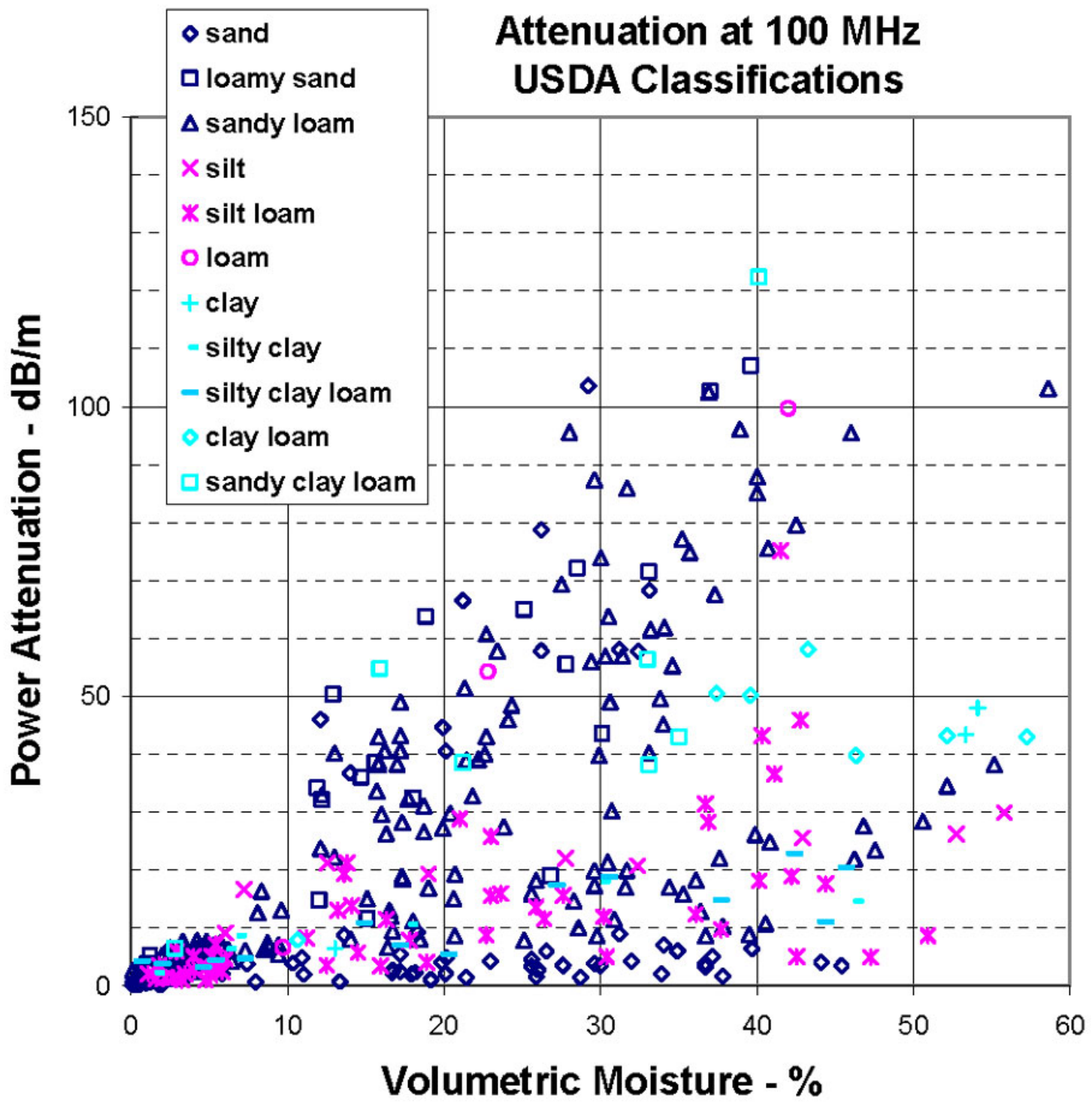

Figure 11. EM power attenuation vs. volumetric moisture at $100 \mathrm{MHz}$ for USDA classifications 


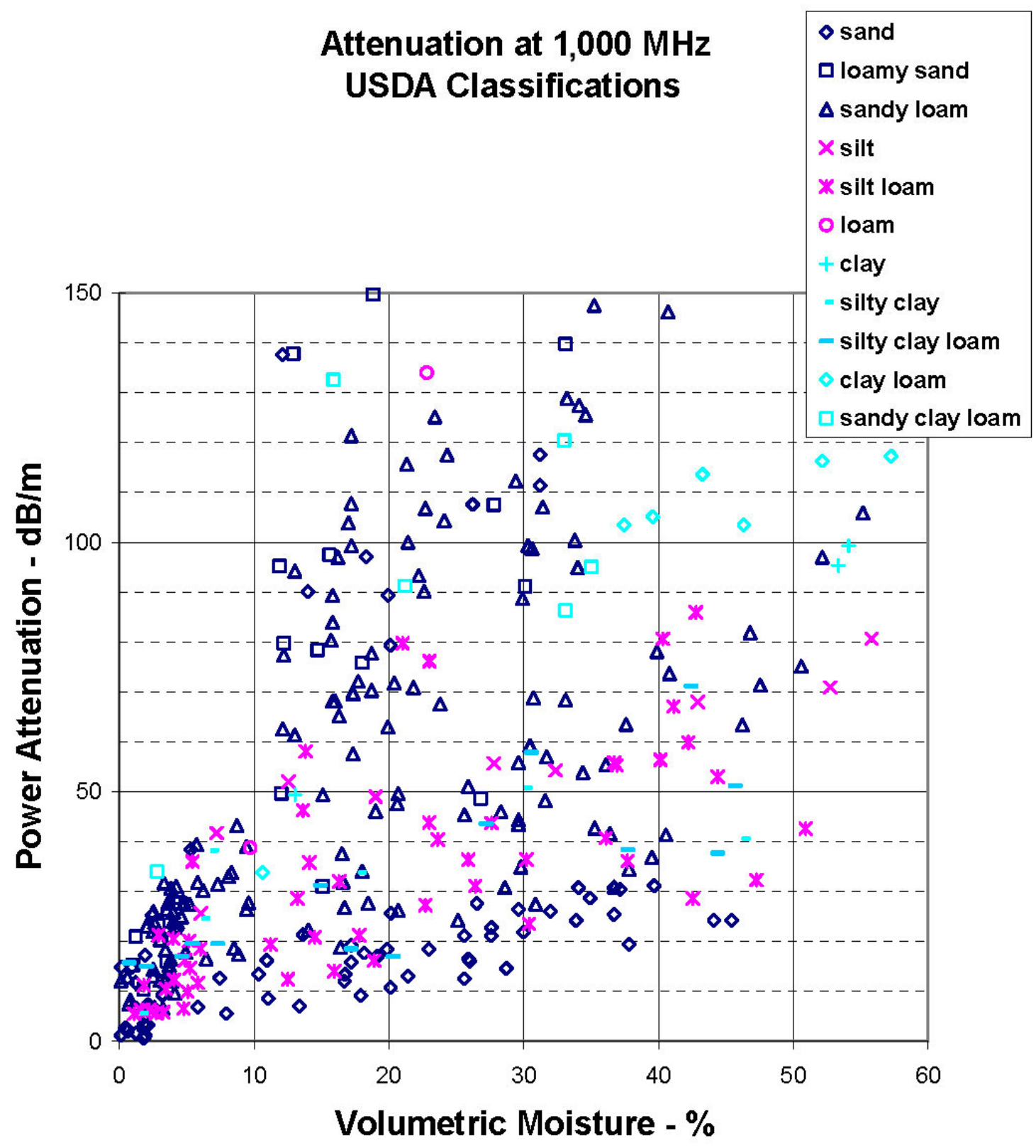

Figure 12. EM power attenuation vs. volumetric moisture at $1,000 \mathrm{MHz}$ for USDA classifications 


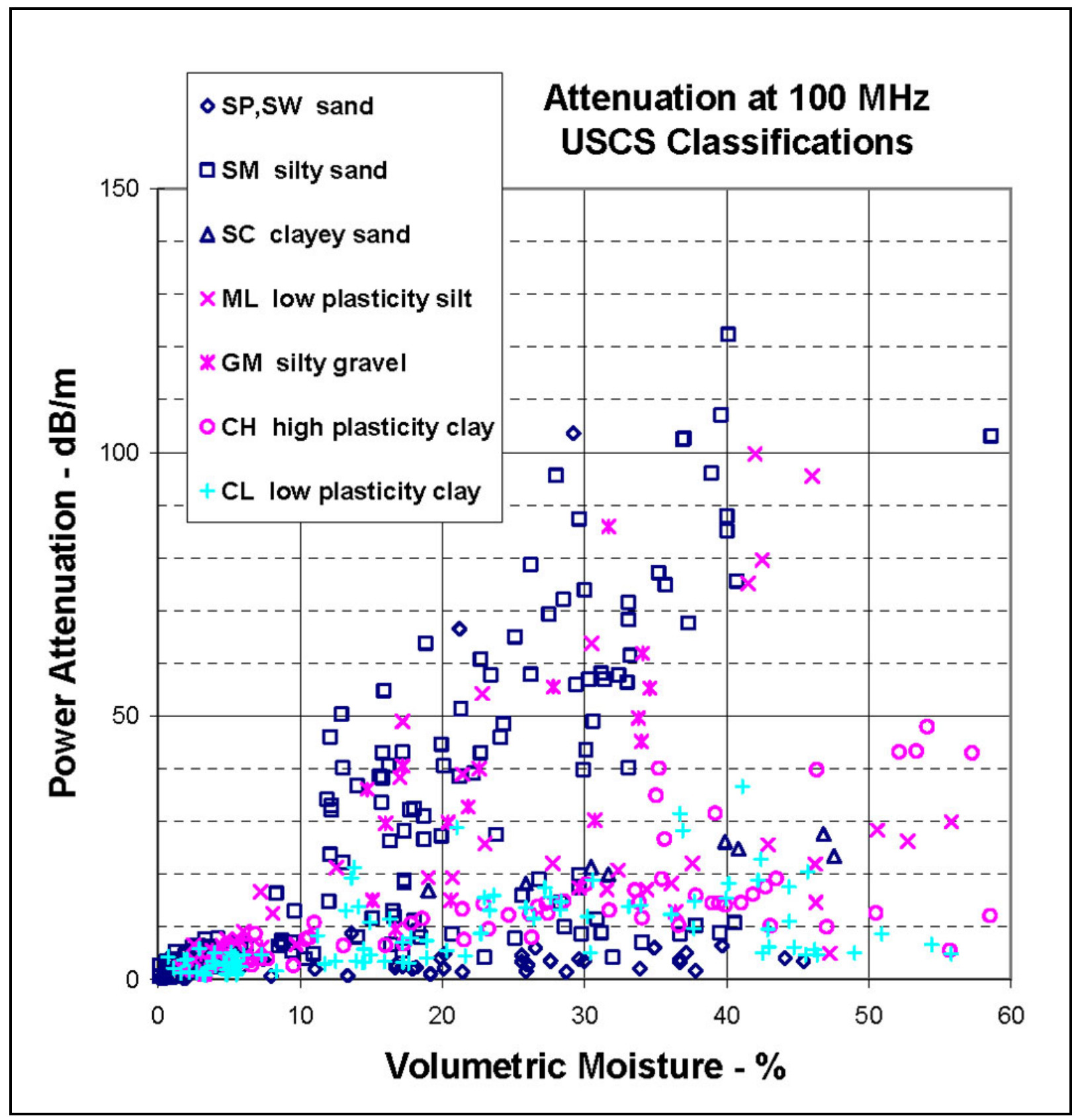

Figure 13. EM power attenuation vs. volumetric moisture at $100 \mathrm{MHz}$ for USCS classifications 


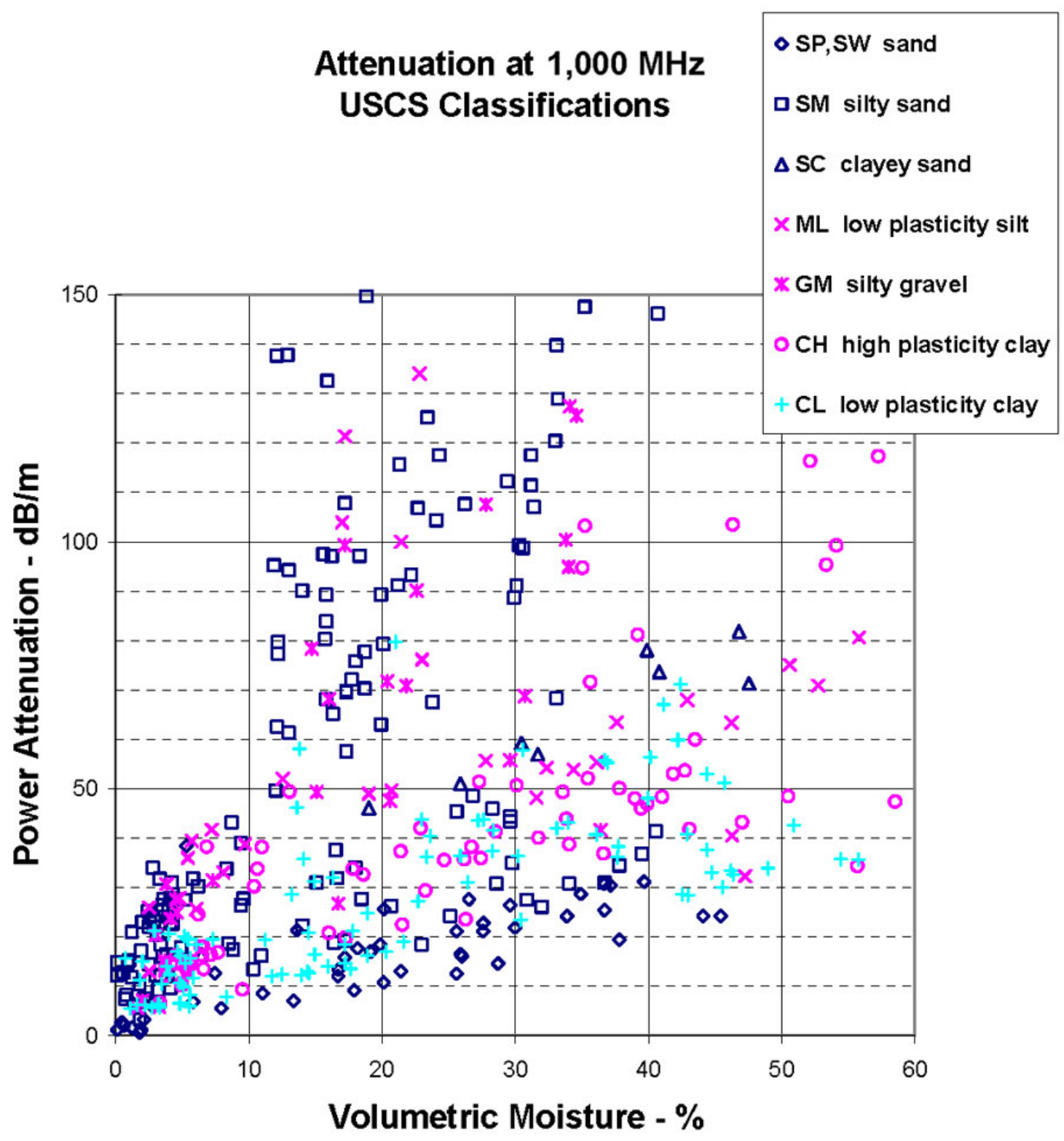

Figure 14. EM power attenuation vs. volumetric moisture at $1,000 \mathrm{MHz}$ for USCS classifications 
If there was a possibility of producing EM power attenuation prediction models at fixed frequencies and for known soil types, then the data shown on these figures would be clustered, or banded, by soil classification. It is obvious from examining these figures that this is not the case. All of the soil classification symbols are mixed throughout each chart.

Another goal of these analyses was to reduce the number of soil classifications so that the engineer or soil scientist in the field would not have to do a precise classification. For example, the hope was that sand, loamy sand, and sandy loam USDA classifications could be consolidated into one classification called sandy soil. Loam, silt loam, and silt might condense into a silty soil classification. All of the other soil types would then be clayey soils. Needless to say, if 12 classifications failed to produce a useful prediction model, it should be no surprise that three classifications would also fail. The same kind of exercise was performed on the USCS classifications with the same results.

Although soil conductivity predictive models have been reported in the literature and discussed in some detail in the first chapter of this report, one must keep in mind that those models were generated for individual soil samples, not for a collection of samples that shared a common classification. The SPSS studies of the ERDC database of soil electrical properties clearly established that accurate EM power attenuation prediction models for broad classes of soils is not achievable.

At this point the decision was made to reexamine the ERDC data from a qualitative perspective with the hope of establishing some sort of guidance that could still be useful to field personnel. These exercises follow.

\section{Bulk Density Effects}

Is it possible that some clustering could be achieved by dividing the data into several bands of bulk density values? Figures 15 and 16 represent plots of EM power attenuation vs. volumetric moisture content for all of the ERDC data at two different frequencies but where the data have been broken into three bulk density bands; namely, values less than $1.4 \mathrm{~g} / \mathrm{cc}$, values between 1.4 and $1.7 \mathrm{~g} / \mathrm{cc}$, and values greater than $1.7 \mathrm{~g} / \mathrm{cc}$. Once again, if bulk density was to be a controlling factor in predicting EM power attenuation, then the data on these charts should be clustered, and they are not. All that one can say is that higher frequencies result in higher attenuation values.

\section{Temperature Effects}

A small amount of ERDC data exists for temperatures other than 20 deg C. While some of those results have been published previously (Curtis 1993), it is probably worth presenting all of the ERDC variable temperature data here to show whether or not soil temperature might provide some guidance to the field engineer/scientist. Unfortunately the results are, once again, inconclusive. 
Figure 15. Bulk density effects on EM power attenuation at $100 \mathrm{MHz}$ and $20 \operatorname{deg} \mathrm{C}$
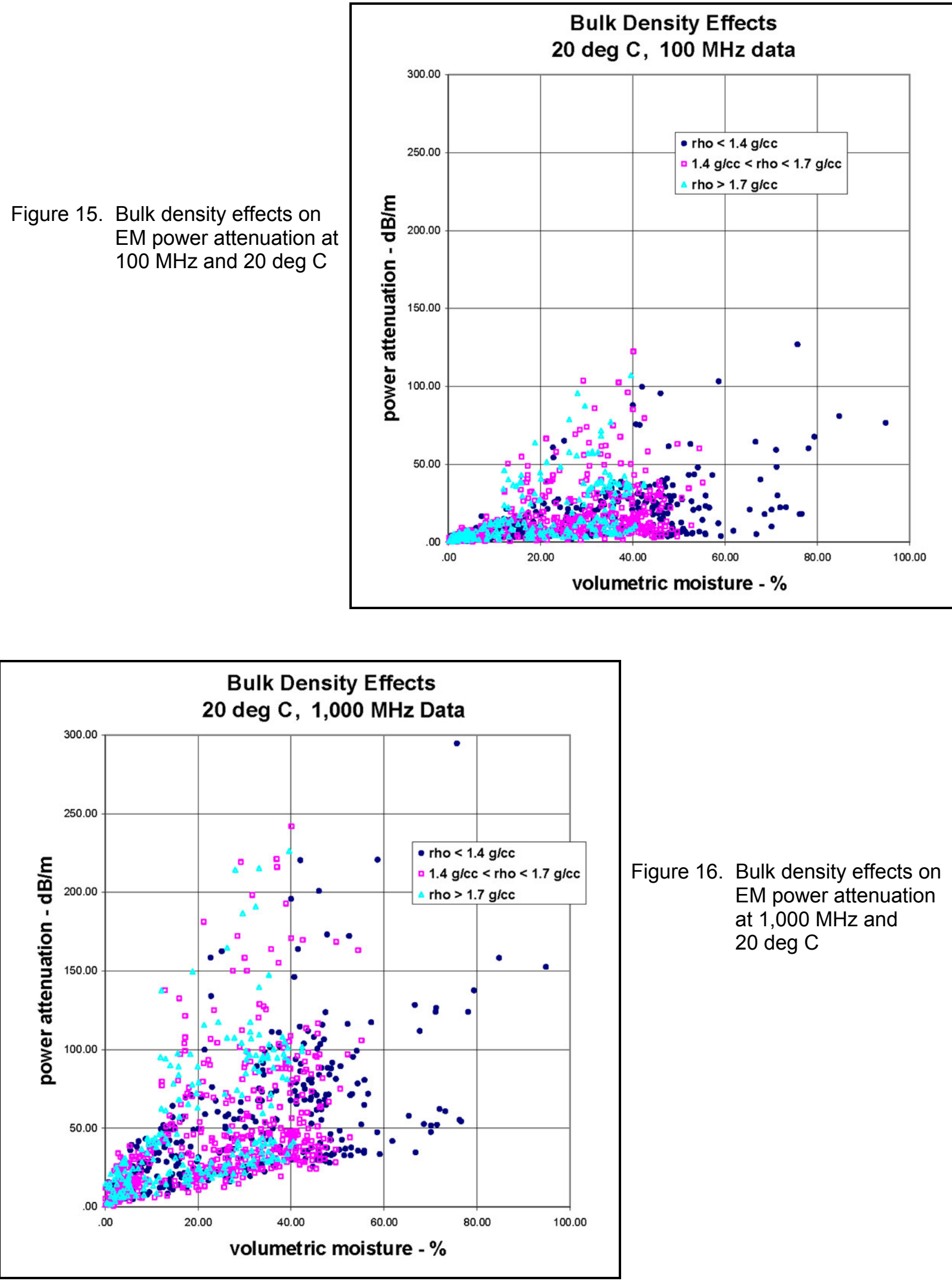

Figure 16. Bulk density effects on EM power attenuation at $1,000 \mathrm{MHz}$ and $20 \operatorname{deg} C$ 
Figures 17 and 18 contain plots of EM power attenuation vs. volumetric moisture content for those few soil samples tested at several temperatures and at frequencies of $100 \mathrm{MHz}$ and 1,000 MHz, respectively. Close examination of Figure $17(100 \mathrm{MHz})$ leads one to the conclusion that increasing soil temperature results in increasing power attenuation. However, $1,000 \mathrm{MHz}$ data shown in Figure 18 produces the opposite conclusion. The most conservative guidance, then, is simply that increasing soil temperature may result in less power attenuation. Assigning numbers to the temperature effect is futile in light of the failure to predict attenuation for a given soil type and system frequency.

\section{Frequency Effects}

Given that regression analyses failed to produce useful EM power attenuation predictive models, and qualitatively determining that neither soil density nor soil temperature had a strong and predictable impact, all that remains is to examine the effects of measurement frequency on power attenuation. Perhaps there will be trends in the data that may be useful for field applications.

Figures 19-24 contain charts of EM power attenuation plotted against volumetric moisture content for several fixed measurement frequencies: $10 \mathrm{MHz}$, $100 \mathrm{MHz}, 500 \mathrm{MHz}, 1,000 \mathrm{MHz}, 5,000 \mathrm{MHz}$, and 10,000 MHz. These charts represent all of the ERDC data collected at those frequencies and at a temperature of $20 \mathrm{deg}$ C. At each frequency one chart is plotted on a linear scale, while the following chart is plotted on a semi-logarithmic scale. The reason for plotting data on a logarithmic scale is to provide a better visualization of the spread of the data. Note also that the vertical scales have been changed on each chart to best view the data.

Consider first, all of the ERDC data collected at $10 \mathrm{MHz}$ and shown on Figure 19a. About 590 data points are plotted on Figure 19a. Included on that chart is a line representing a linear least squares fit to the data. Note how poor the fit is $\left(\mathrm{R}^{2}=0.112\right)$. Clearly the linear fit could not be used as a predictive model, because it would seriously underpredict values of attenuation. For example, at 20 percent volumetric moisture, the model would predict about 5 $\mathrm{dB} / \mathrm{m}$ of attenuation. However, it is clear from the data that a large number of soil samples demonstrated far less attenuation.

On a logarithmic scale (Figure 19b), one can readily see a lower bound on the data. This is potentially a useful tool in the sense that it gives field personnel a conservative lower estimate on power attenuation. For the case of a sensor operating at $10 \mathrm{MHz}$, that conservative estimate for EM power attenuation might be roughly $1 \mathrm{~dB} / \mathrm{m}$, which is not a significant amount of attenuation. Experience has shown that low-frequency systems can penetrate much deeper into soils than do high-frequency systems. These attenuation numbers support that observation. 
Figure 17. Temperature effects on EM power attenuation at $100 \mathrm{MHz}$ and $20 \mathrm{deg} \mathrm{C}$
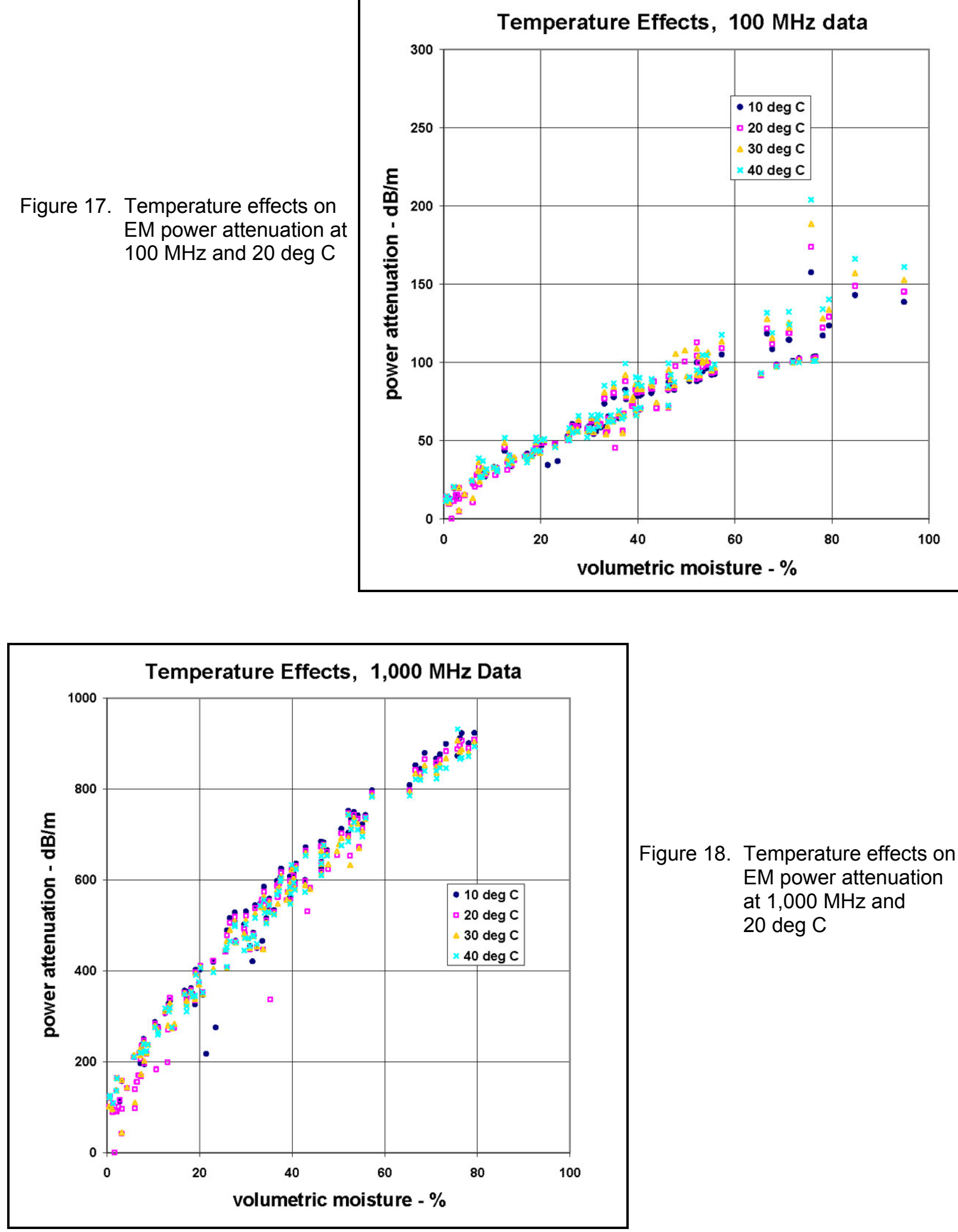

Figure 18. Temperature effects on EM power attenuation at $1,000 \mathrm{MHz}$ and $20 \operatorname{deg} C$ 
Figure 19a. EM power attenuation vs. volumetric moisture at $10 \mathrm{MHz}$ and $20 \mathrm{deg} \mathrm{C}$

\section{Power Attenuation vs Moisture Content All ERDC Samples $10 \mathrm{MHz}$ Data}
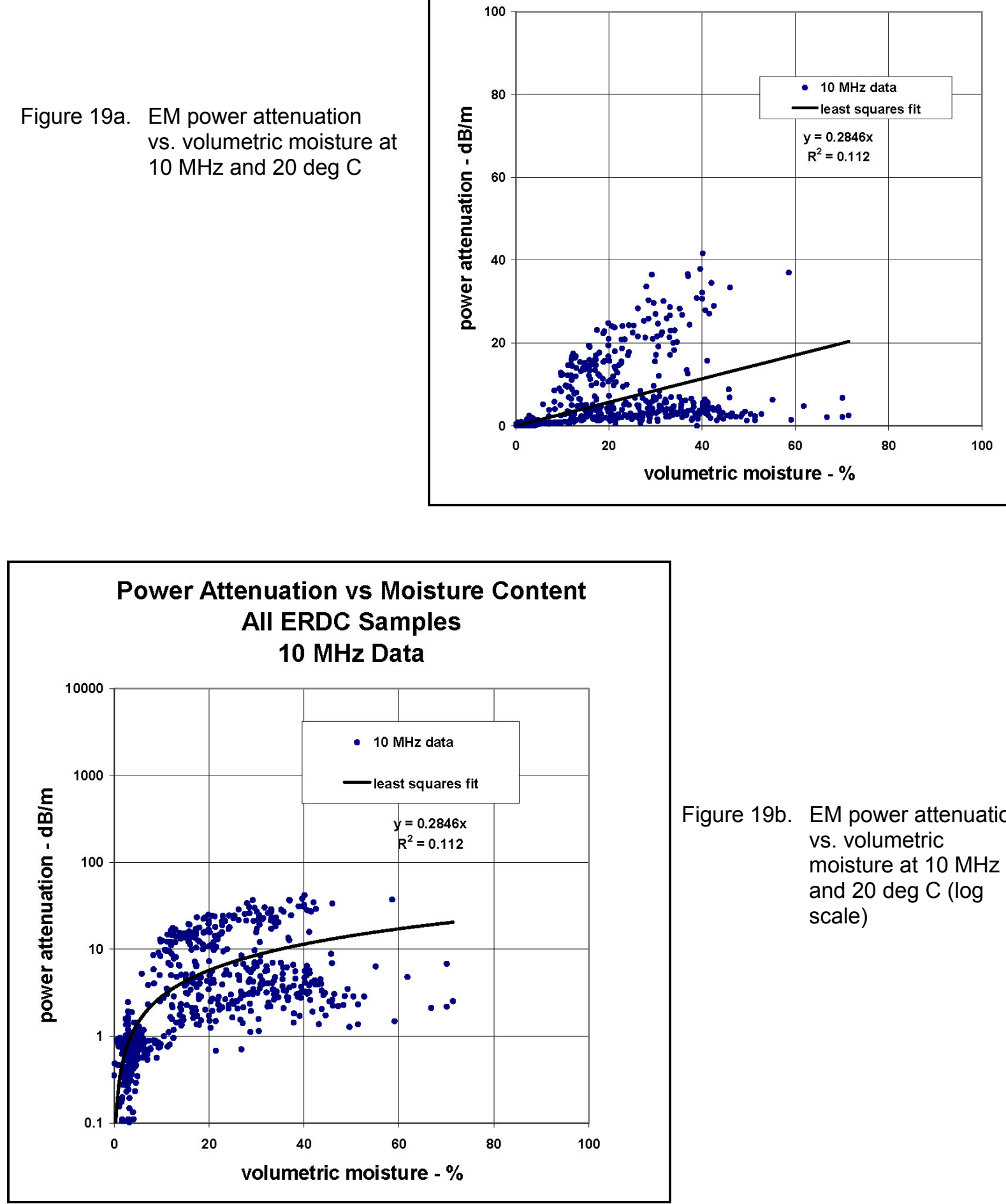

Figure 19b. EM power attenuation vs. volumetric moisture at $10 \mathrm{MHz}$ and 20 deg $C(\log$ scale) 
Figure 20a. EM power attenuation vs. volumetric moisture at $100 \mathrm{MHz}$ and $20 \operatorname{deg} \mathrm{C}$

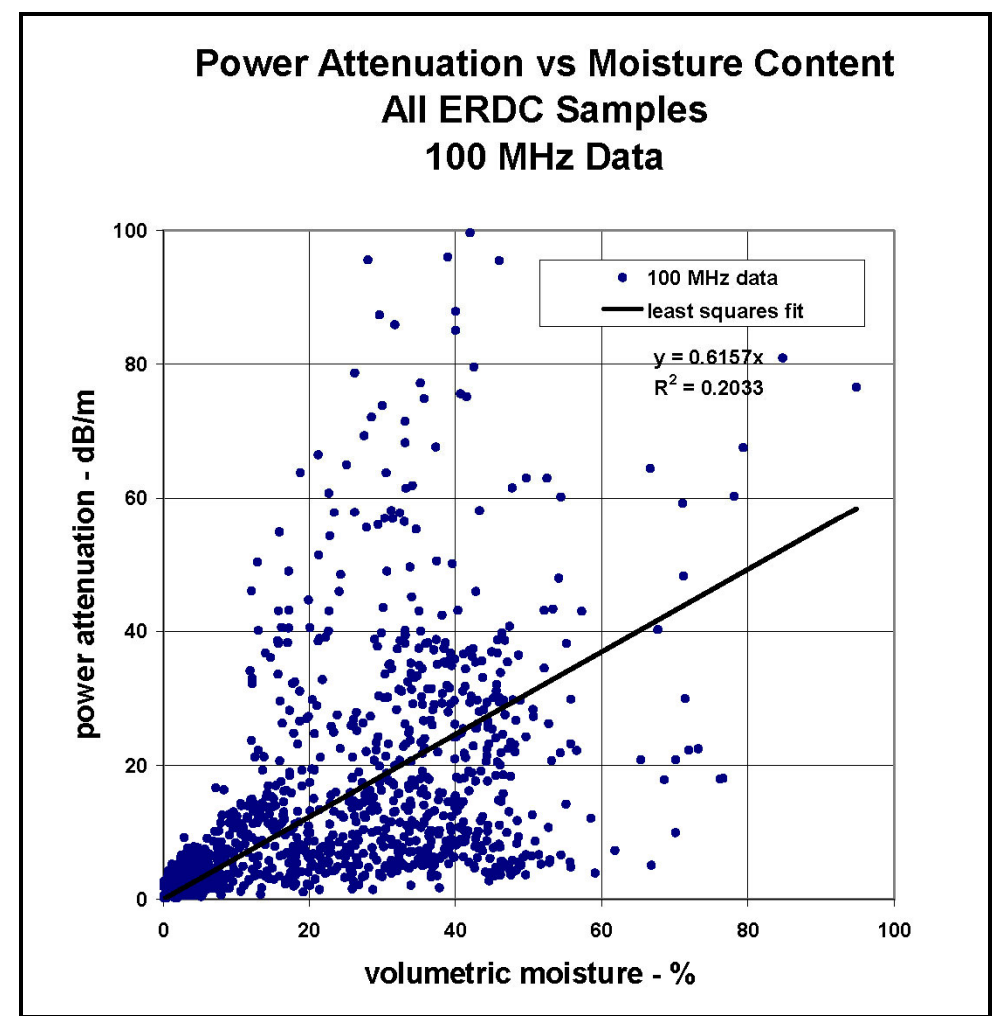

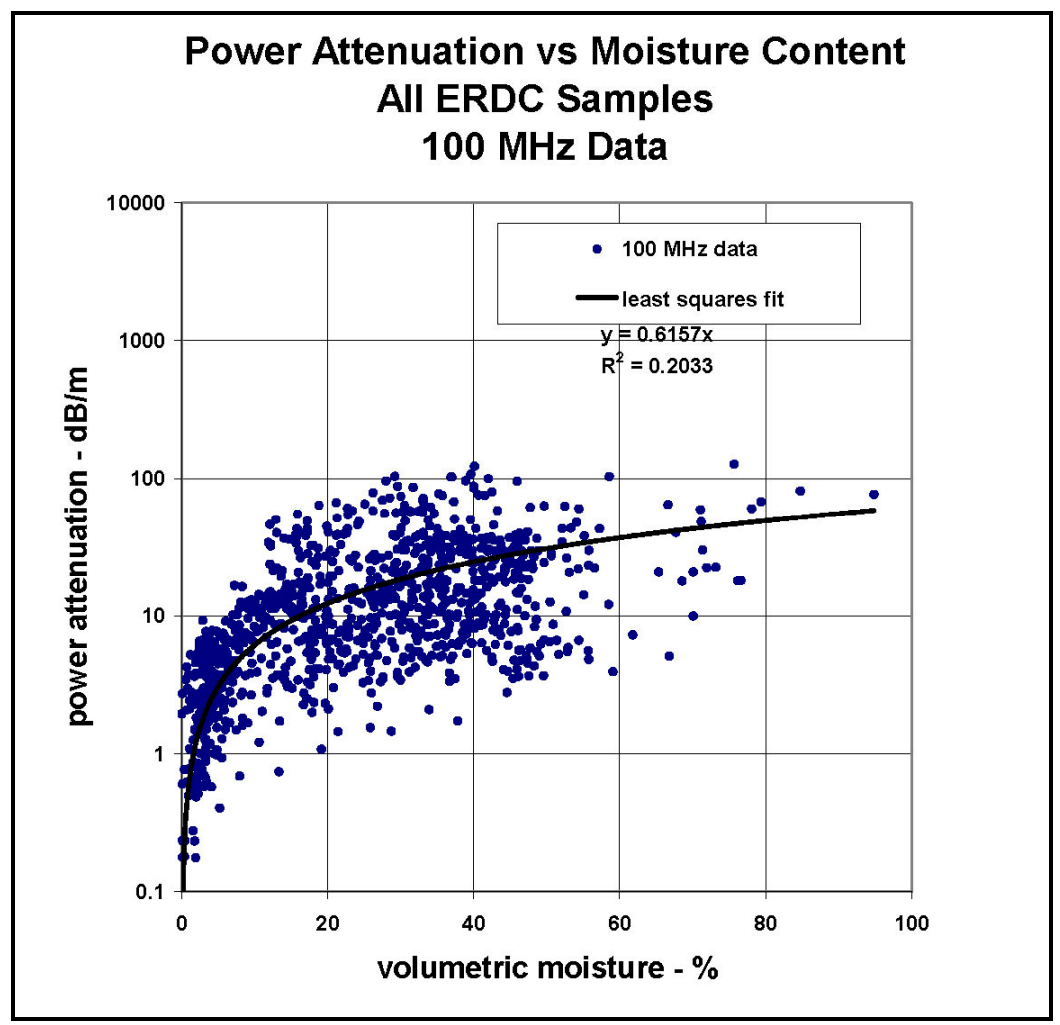

Figure 20b. EM power attenuation vs. volumetric moisture at $100 \mathrm{MHz}$ and $20 \operatorname{deg} C$ (log scale) 
Figure 21a. EM power attenuation vs. volumetric moisture at 500 $\mathrm{MHz}$ and $20 \operatorname{deg} C$
Power Attenuation vs Moisture Content All ERDC Samples $500 \mathrm{MHz}$ Data

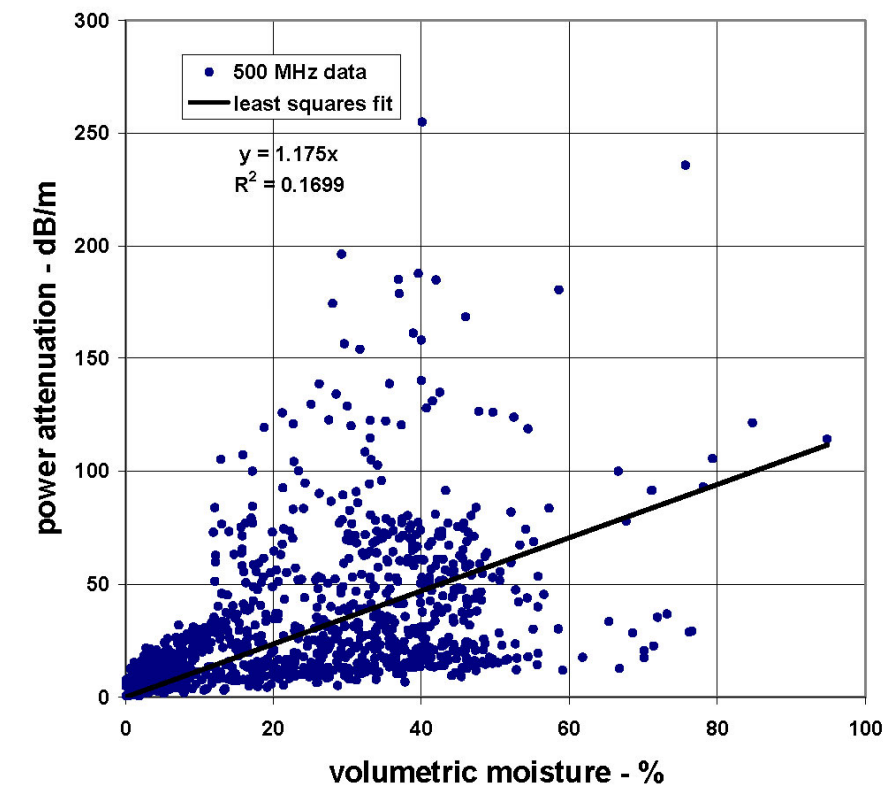

Power Attenuation vs Moisture Content All ERDC Samples $500 \mathrm{MHz}$ Data

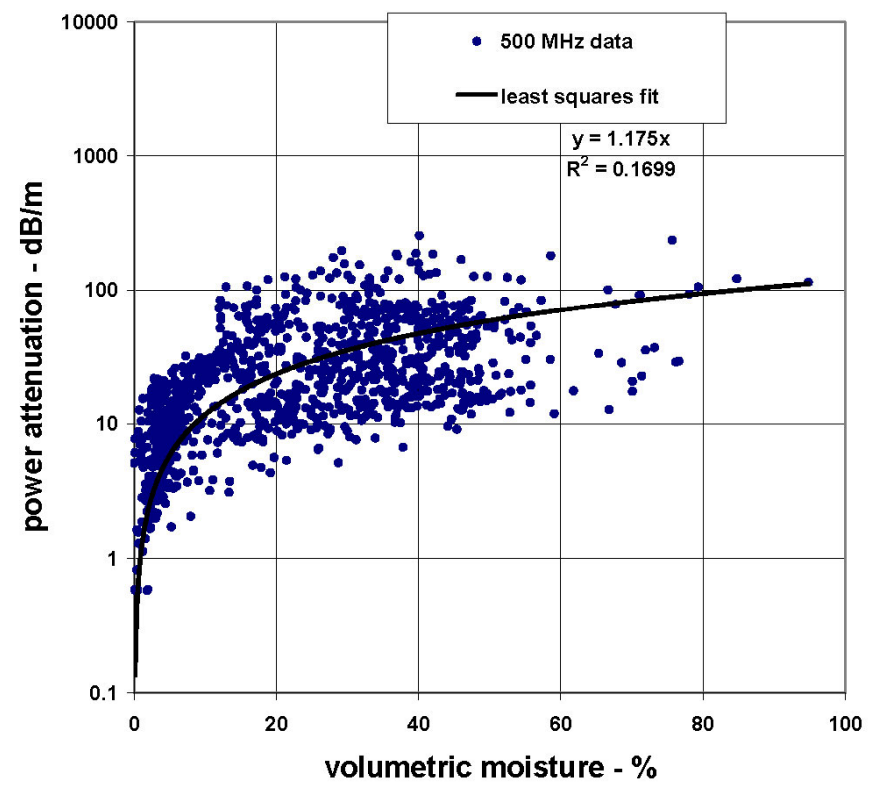

Figure 21b. EM power attenuation vs. volumetric moisture at $500 \mathrm{MHz}$ and 20 deg $\mathrm{C}$ (log scale) 
Figure 22a. EM power attenuation vs. volumetric moisture at $1,000 \mathrm{MHz}$ and $20 \operatorname{deg} C$
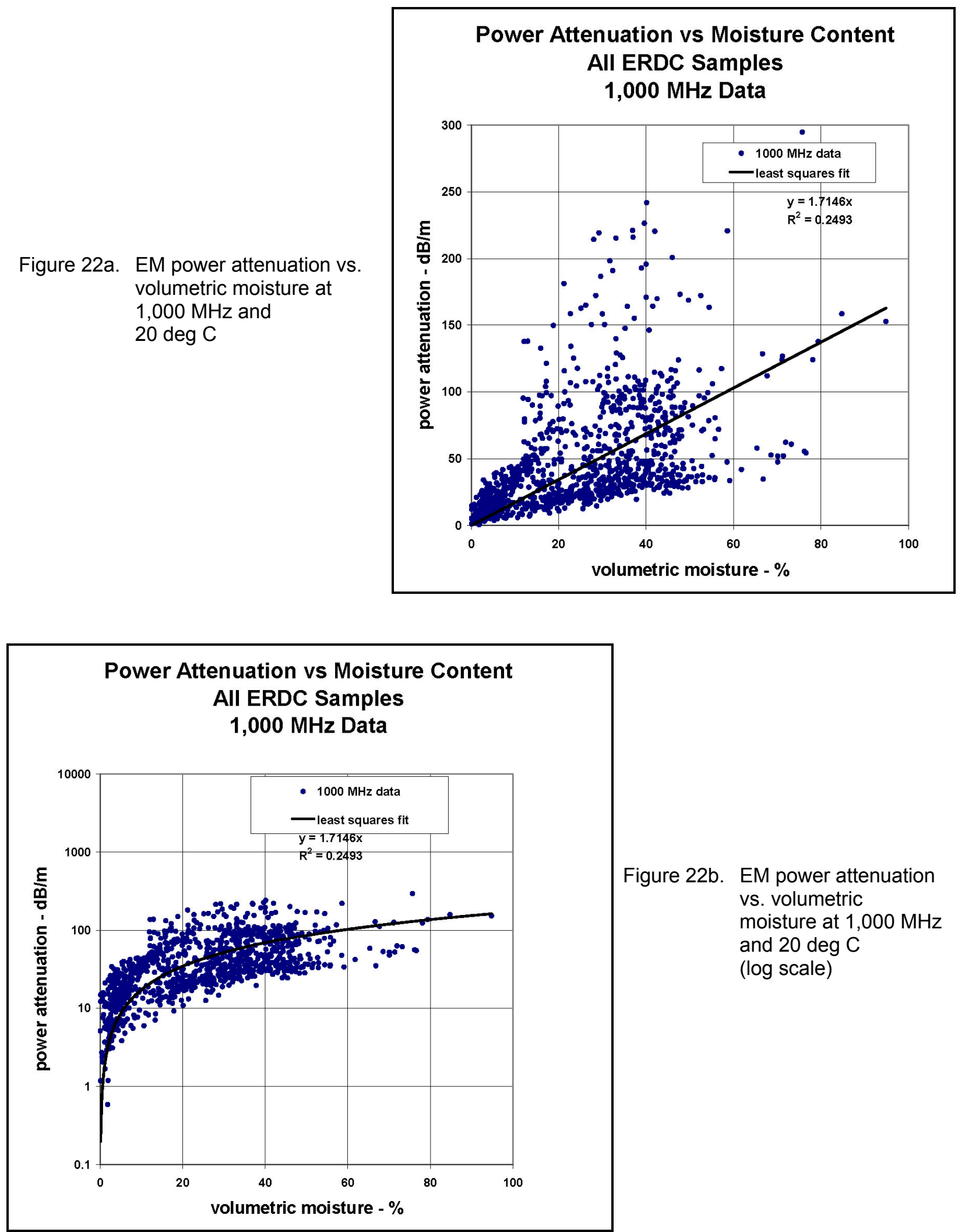

Figure 22b. EM power attenuation vs. volumetric moisture at $1,000 \mathrm{MHz}$ and 20 deg $C$ (log scale) 
Figure 23a. EM power attenuation vs. volumetric moisture at $5,000 \mathrm{MHz}$ and $20 \operatorname{deg} C$
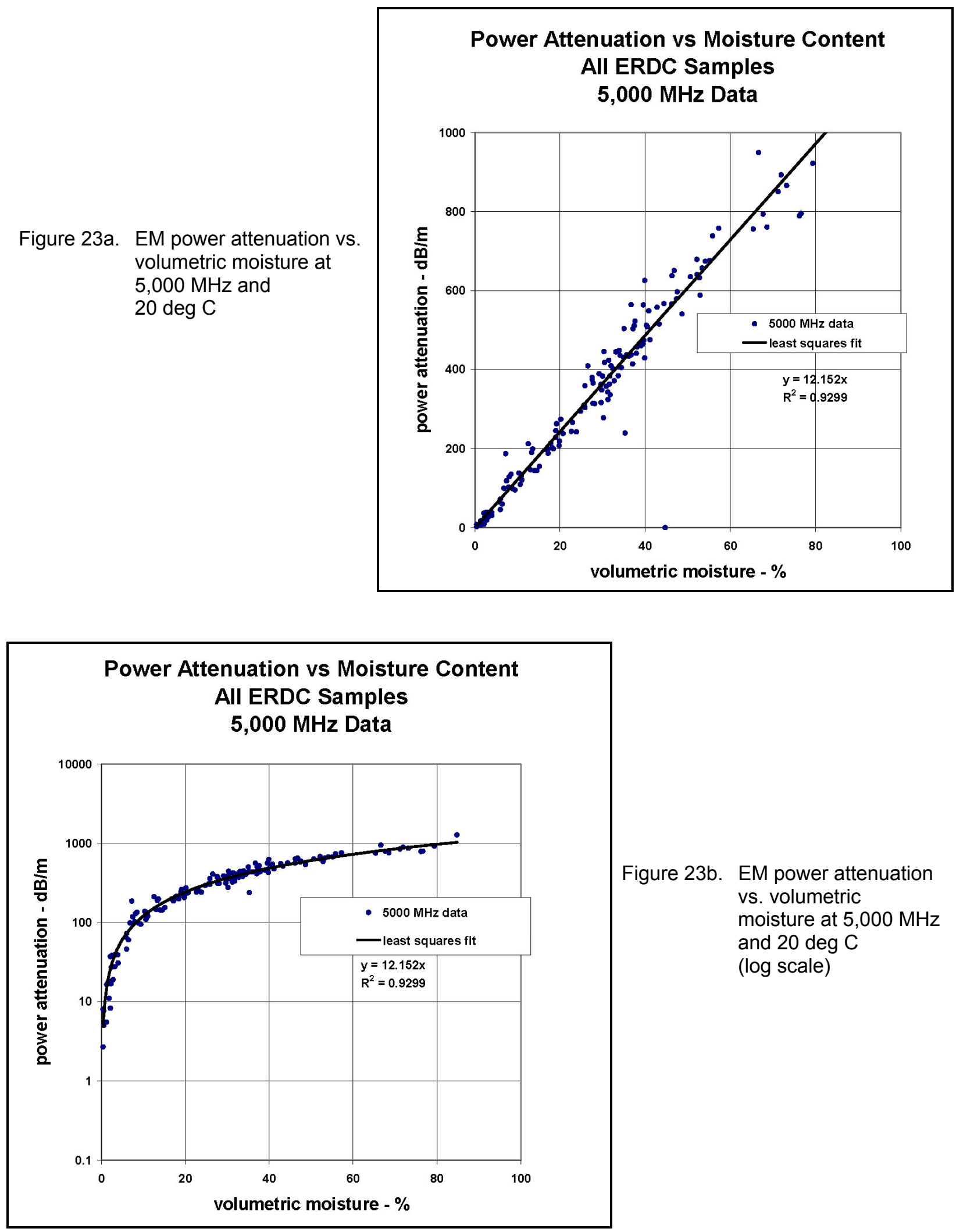

Figure 23b. EM power attenuation vs. volumetric moisture at $5,000 \mathrm{MHz}$ and $20 \operatorname{deg} \mathrm{C}$ (log scale) 
Figure 24a. EM power attenuation vs. volumetric moisture at $10,000 \mathrm{MHz}$ and $20 \operatorname{deg} C$

\section{Power Attenuation vs Moisture Content All ERDC Samples $10,000 \mathrm{MHz}$ Data}

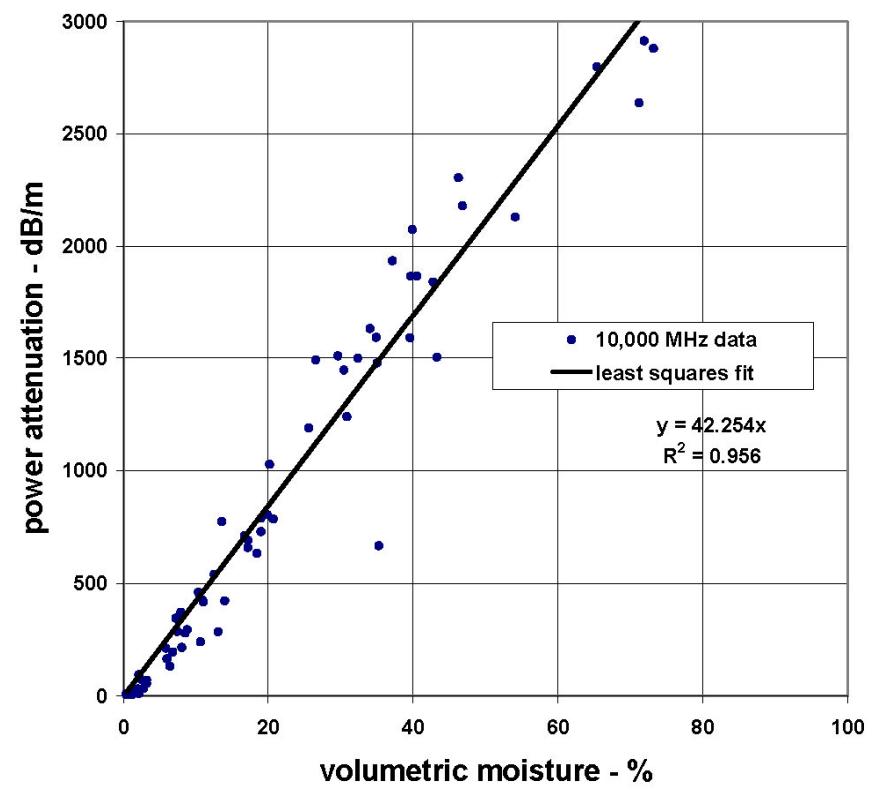

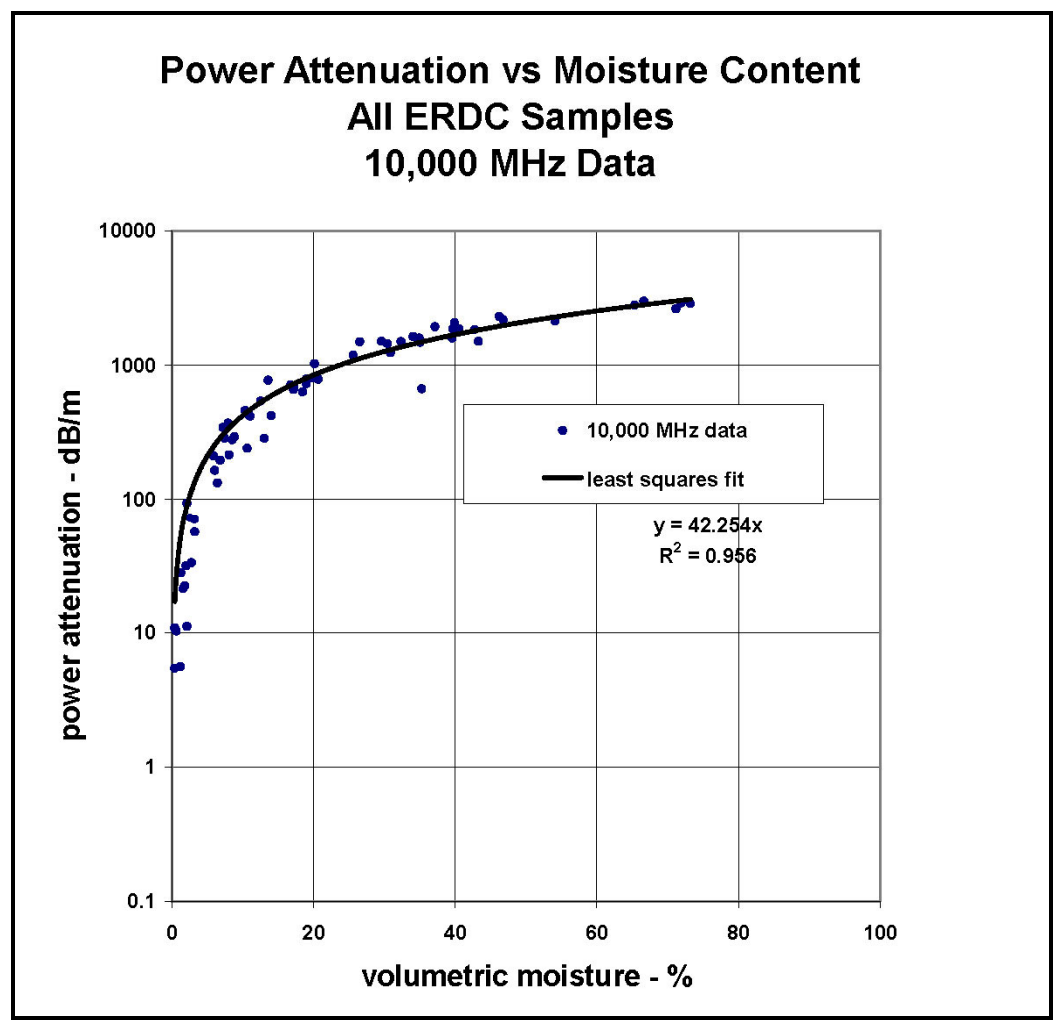

Figure 24b. EM power attenuation vs. volumetric moisture at 10,000 $\mathrm{MHz}$ and $20 \operatorname{deg} \mathrm{C}$ (log scale) 
Figures 20a and 20b show attenuation data at $100 \mathrm{MHz}$ (about 1,080 data points). As before, the linear regression model is not $\operatorname{good}\left(\mathrm{R}^{2}=0.2033\right)$. Note also that the average power attenuation at $100 \mathrm{MHz}$ is more than twice the attenuation at $10 \mathrm{MHz}$. A close examination of the logarithmic chart (Figure 20b) reveals at least two interesting characteristics of the attenuation data. One is that at low moisture conditions (less than 5 percent volumetric moisture), the soils tested exhibited a huge variation in power attenuation; however, if one needs to be conservative, the lower limit of that attenuation is certainly quite low. The second observation is that if one wanted to place a fairly conservative estimate on power attenuation at normal moisture contents and for much wetter soils, that number could easily be chosen at a value of say, 2 or $3 \mathrm{~dB} / \mathrm{m}$.

Figures 21a and $21 \mathrm{~b}$ show $500 \mathrm{MHz}$ of data (again representing about 1,080 data points). The linear regression model is no better at $500 \mathrm{MHz}$ than it was at $100 \mathrm{MHz}$; however, the average attenuation has nearly doubled for the higher frequency data. Other than for the lowest values of moisture content, one could argue that a reasonably conservative estimate of power attenuation might be on the order of $5 \mathrm{~dB} / \mathrm{m}$ at $500 \mathrm{MHz}$.

The linear regression model for $1,000 \mathrm{MHz}$ data (Figures 22a and 22b) is a slight improvement over the $500 \mathrm{MHz}$ model, but it is still not a useful predictive tool. A conservative attenuation value of $10 \mathrm{~dB} / \mathrm{m}$ or more is possible for normal to high moisture contents. Figures $22 \mathrm{a}$ and $22 \mathrm{~b}$ also contain about 1,080 data points.

It is not until one examines the higher frequency data at 5,000 $\mathrm{MHz}$ (Figures $23 \mathrm{a}$ and $23 \mathrm{~b})$ that one sees a reasonably good linear regression model $(\mathrm{R}=$ 0.9299). There are, however, a number of caveats that must be stipulated along with that observation. One is that far fewer data points existed for the 5,000 $\mathrm{MHz}$ frequency (approximately 150). In fact, these data represent soils for one major field sampling collection, along with about a dozen "laboratory" soils whose particle-size distribution curves were highly variable, but whose chemistry differences might not have been extreme.

The same arguments hold for the 10,000 MHz data (Figures 24a and 24b), which represent only about 65 data points and are limited mostly to the "laboratory" soils. In other words, all that can be said about the highest frequency data is that average attenuation values continue to rise as the frequency goes up. Care should be taken in extrapolating those results to dry soils. All of the data clearly show that for the driest of soils, one can expect significant penetration of the EM signal. 


\section{Summary and Recommendations}

The goal of this study was to determine if EM power attenuation prediction models could be developed for soils that required only a minimum of easily obtained input parameters. Field crews using high-power electromagnetic devices to detect and/or discriminate buried unexploded ordnance (UXO) need to know whether or not the power levels of their equipment are sufficient to detonate UXO fuzes. Knowing the power level of their transmitters and the attenuation factor for the soil they are penetrating, they could predict power levels at the anticipated depths of UXO.

Factors that affect EM attenuation include sensor operating frequency, soil chemistry, moisture content, soil temperature, and bulk density. Based on the author's experience in measuring soil electrical properties, the original hope for this study was that useful models could be executed using soil type, frequency, and moisture content as a minimum set of input parameters.

Since the early 1990s complex dielectric properties of more than 300 distinct soil samples have been measured at ERDC in Vicksburg, MS. A dozen, or so, of these soils were obtained from the ERDC Geotechnical Laboratory; and, while they cannot be classified as artificial soils, they were certainly processed to remove organic material and gravel-sized particles. Another group of five soils came from the U.S. Natural Resources Conservation Service and can be referred to as "benchmark" soils. The remainder of the soils were all obtained from numerous field sites in this country as well as from some foreign sites. A variety of frequency bands were required for different customers. Some data were collected at several sample temperatures; most were collected at $20 \mathrm{deg}$ C. The dielectric properties of each sample were measured for at least three different volumetric moisture contents. Sample density could not be controlled in these experiments; therefore, a broad range of random sample densities were achieved. In summary, at selected frequencies, more than 1,000 EM power attenuation data points were available for modeling studies.

Not all of the soils tested at ERDC were classified at the time that their dielectric properties were being measured. However, the author was able to recover one of two different classifications for many of the samples, and both classifications for a number of samples. One classification scheme is that used by the U.S. Department of Agriculture. Naturally its objective is to be able to 
compare soils from different parts of the world in terms of their ability to sustain crop growth. The USDA classification scheme can be visualized as a soil texture triangle, within which a soil is classified according to its relative percentages of sand and clay-sized particles. The second classification scheme is one used by the U.S. Army Corps of Engineers and referred to as the Unified Soil Classification System. USCS soils are labeled according to their performance as load-bearing construction materials.

The initial effort at developing EM power attenuation prediction models involved numerous attempts to perform multiple parameter linear regression analyses of the ERDC data. These efforts, which met with no success, focused on trying to develop predictive models for each soil classification at set frequencies, a single sample temperature, and utilizing moisture content and bulk density as input parameters. Data charts were shown in Chapter 3 that clearly demonstrated that soil type could not be used to consistently or definitively predict EM power attenuation. Similar charts revealed that neither sample density nor sample temperature provided any data clustering when all of the soil types were displayed on a single chart.

Following the failure of the statistical analyses to generate the desired predictive models, the total ERDC data set was revisited at each of five frequencies, and a simple linear regression was performed. High-frequency data $(>1 \mathrm{GHz})$ showed reasonably good model fits, but probably only because the soils tested at those frequencies were of the processed variety. It was concluded, however, that the data charts for all of the frequencies could be used to provide a conservative lower bound on power attenuation. In light of that observation, the following table has been generated from the data charts shown in Figures 19-24. For each of the six selected frequencies, the linear regression model was used to identify an average attenuation at 10 percent volumetric soil moisture content. The figure of 10 percent was selected by the author as a typical in situ moisture value for near-surface soils at most temperate locales. Upon examining the spread of the data at each frequency and at the 10 percent moisture value, a column of conservative attenuation values was generated and included in the table. These are values that would provide some degree of safety for field crews operating high-power sensing equipment in the presence of UXO.

\section{Table 1}

Frequency-Dependent EM Power Attenuation Values

\begin{tabular}{||l|l|l||}
\hline \hline Frequency (MHz) & $\begin{array}{l}\text { Average Attenuation at 10\% } \\
\text { Volumetric Moisture (dB/m) }\end{array}$ & $\begin{array}{l}\text { Conservative Attenuation } \\
\text { Estimate at 10\% Volumetric } \\
\text { Moisture (dB/m) }\end{array}$ \\
\hline \hline 10 & 3 & 1 \\
\hline 100 & 6 & 2 \\
\hline 500 & 12 & 4 \\
\hline 1,000 & 17 & 10 \\
\hline 5,000 & 122 & 100 \\
\hline 10,000 & 422 & 300 \\
\hline
\end{tabular}


While the information in Table 1 may be useful guidance in a general sense, it does not substitute for laboratory evaluation of test site soil properties. The only definitive approach to providing a safe work environment is to collect numerous near-surface and below-surface samples and transport them to a laboratory where EM power attenuation measurements can be made at the appropriate frequency. 


\section{References}

Archie, G. E. (1942). "The electrical resistivity log as an aid in determining some reservoir characteristics," Transactions of the A.I.M.E. 146, 54-62.

Campbell, J. E. (1990) "Dielectric properties and influence of conductivity in soils at one to fifty megahertz," Soil Science Society of America Journa 54, 332-341.

Cooke, J. A., and Gladwin, M. T. (2004). "Ground penetrating radar performance in typical Australian soils," taken from the "Minescale Geophysics" page of the Australian Commonwealth Scientific and Industrial Research Organization (CSIRO) Web site: www.cat.csiro.au/dem $/ \mathrm{msg} / \mathrm{scirev} / \mathrm{scirev} \cdot \mathrm{html} \# \mathrm{GPR}$.

Curtis, J. O. (1993). "Microwave dielectric behavior of soils; Report 3, Measurements and modeling," Technical Report EL-93-25, U.S. Army Engineer Waterways Experiment Station, Vicksburg, MS.

Curtis, J. O. (2001a). "Moisture effects on the dielectric properties of soils," IEEE Transactions on Geoscience and Remote Sensing 39(1), 125-128.

Curtis, J. O. (2001b). "A durable laboratory apparatus for the measurement of soil dielectric properties," IEEE Transactions on Instrumentation and Measurement 50(5), 1364-1369.

Hallikainen, M. T., et al. (1985). "Microwave dielectric behavior of wet soil -Part I: Emperical models and experimental observations," IEEE Transactions on Geoscience and Remote Sensing GE-23(1), 25-34.

Hewlett Packard, "Test \& Measurement Application Note 95-1, S-Parameter Techniques," Web site: www.hp.com/go/tmappnotes

Hipp, J. E. (1974). "Soil electromagnetic parameters as functions of frequency, soil density, and soil moisture," Proceedings of the IEEE 62(1), 98-103.

Hoekstra, P., and Delaney, A. (1974). "Dielectric properties of soils at UHF and microwave frequencies," Journal of Geophysical Research 79(11), 16991708 . 
Hulse, W. H., Walker, J. W., and Pearce, D. C. (1972). "Electrical conductivity studies of the soils of the Middle Atlantic Region: Virginia," Research and Technical Development Report ECOM-3564, U.S. Army Electronics Command, Fort Monmouth, NJ.

Marinelli, V., DeLuca, C., and Ressler M. (1999). "UXO detection using ultrawideband synthetic aperture radar" paper presented at UXO Forum "99, May 25-27, Atlanta, GA.

Miller, T. W., Hendrickx, J. M. H., and Borchers, B. (2002). "Radar detection of buried landmines in field soils," draft paper submitted for publication.

Nicolson, A. M., and Ross, G. F. (1970). "Measurement of the intrinsic properties of materials by time-domain techniques," IEEE Transactions on Instrumentation and Measurement IM-19(4), 377-382.

Portland Cement Association (1973). PCA soil primer, Skokie, IL

Smith, S. S., and Arunlanandan, K. (1981). "Relationship of electrical dispersion to soil properties," Journal of the Geotechnical Engineering Division, Proceedings of the American Society of Civil Engineers GT5, 591-604.

Topp, G. C., Davis, J. L., and Annan, A. P. (1980). "Electromagnetic determination of soil water content: Measurements in coaxial transmission lines," Water Resources Research 16, 574-582.

U.S. Army Engineer Waterways Experiment Station (now ERDC). (1960). "The Unified Soil Classification System," Technical Memorandum No. 3-357, Vicksburg, MS. 


\section{Appendix A Soil Dielectric Property Data Collection and Analysis Procedures}

\section{Complex Dielectric Property Measurements}

From about 1990 until the present, the complex dielectric constant of soils has been measured by the author at the U.S. Army Engineer Research and Development Center, Vicksburg Site, utilizing a Hewlett-Packard 8753E Network Analyzer System (and an earlier HP8510C) with a coaxial sample holder (Curtis 2001b). ${ }^{1}$ The idealized geometry used for these measurements is a sample of length, $d$, in a coaxial holder. The complex relative dielectric constant and complex relative magnetic permeability of a sample are labeled $\varepsilon$ and $\mu$, respectively. Complex S-parameter data are collected at selected frequencies and stored on a laboratory data controller. The parameter, $S_{11}$, is the complex ratio of reflected voltage to incident voltage at one end of the sample (with the other end electronically shorted), while the parameter, $S_{21}$, is the complex ratio of voltage measured on the other end of the sample to the same incident voltage (an idealized transmission coefficient).

The use of S-parameters as measurement tools for electronic devices was introduced in the 1960s (Hewlett Packard). In 1970, a paper was published that described the use of coaxial samples and S-parameter measurements to determine the complex dielectric and magnetic properties of a material (Nicolson and Ross 1970). The model can be summarized:

$$
\varepsilon=\sqrt{\frac{c_{2}}{c_{1}}}
$$

and

\footnotetext{
${ }^{1}$ References cited in this appendix are located at the end of the main text.
} 


$$
\mu=\sqrt{c_{1} c_{2}}
$$

where

$$
\begin{aligned}
& c_{1}=\frac{\mu}{\varepsilon}=\left(\frac{1+\Gamma}{1-\Gamma}\right)^{2} \\
& c_{2}=\varepsilon \mu=-\left\{\frac{c}{\omega d} \ln \left(\frac{1}{z}\right)\right\}^{2} \\
& z=\frac{V_{1}-\Gamma}{1-V_{1} \Gamma} \\
& \Gamma=X \pm \sqrt{X^{2}-1} \quad \text { (smallest value) } \\
& X=\frac{1-V_{1} V_{2}}{V_{1}-V_{2}} \\
& V_{1}=S_{21}+S_{11}
\end{aligned}
$$

and

$$
V_{2}=S_{21}-S_{11}
$$

$c$ is the speed of light in a vacuum, and $\omega$ is the angular frequency of the signal. Implied in this model is the assumption that the sample holder has no intrinsic magnetic properties. This is undoubtedly not true for the sample holders used in this project. In fact, the center conductor for the sample holders are made of a steel alloy, and the connectors at the ends of the sample holders are not precision, low-loss devices. Nevertheless, measurements of empty sample holders (air) and holders filled with distilled, deionized water give very acceptable results. If one is able to confidently assume that the material being measured is nonmagnetic, then the complex dielectric constant can be calculated directly from Equation A4.

\section{Calculation of Additional Parameters}

While the complex dielectric constant and complex magnetic permeability are, by themselves, meaningful properties of any material, it is possible to generate from them other useful parameters that are more readily utilized by engineers and scientists. For example, in the design of ground-penetrating radar systems, what may be most useful to the engineer is how rapidly the soil attenuates the signal. Attenuation, coupled with the sensitivity of the receiver, determines the effective depth of penetration for the radar in a particular soil. 
Similarly, a clear understanding of how the speed of an electromagnetic wave varies with depth and lateral position at any given test site determines how well the radar data can be processed to produce an accurate assessment of subsurface conditions. The following paragraphs outline the generation of several useful parameters from complex dielectric properties, including power attenuation, phase velocity, and an equivalent electrical conductivity.

Assuming plane harmonic wave propagation in a lossy, unbounded medium, the wave amplitude function may be written:

$$
e^{i(k x-\omega t)}
$$

where

$$
\begin{aligned}
k=\beta+i \alpha=\omega N / c & =\text { complex propagation constant, } \\
\beta & =\text { phase constant, } \\
\alpha & =\text { amplitude attenuation factor, } \\
\omega & =\text { radial frequency, } \\
N & =\text { complex index of refraction, } \\
c & =\text { velocity of light in a vacuum, } \\
i & =\text { symbol designating an imaginary quantity }=\sqrt{-1}, \\
x & =\text { space coordinate, and } \\
t & =\text { time }
\end{aligned}
$$

For the sake of simplicity, let the medium be nonmagnetic. Then,

$$
N^{2}=\varepsilon=\varepsilon^{\prime}+i \varepsilon^{\prime \prime}
$$

where, as stated above, $\varepsilon$ is the relative complex dielectric constant. The dielectric constant, along with the electrical conductivity from Ohm's Law, represents the electrical properties of the medium. Conductivity, $\sigma$, accounts for current flow in the sample because of free charged particle motion; whereas, the real part of the dielectric constant, $\varepsilon^{\prime}$, accounts for Maxwell's "displacement currents" because of the electric polarization of the medium and to the time rateof-change of the electric field. When both conduction and displacement currents are considered, one finds two terms in Ampere's law for current flow that represent losses (or a shift in phase), one containing the electrical conductivity and one containing the imaginary part of the dielectric constant. While these two terms account for different loss mechanisms, most researchers use only one term or the other to identify losses. Many users prefer to deal with the concept of electrical conductivity. However, the algorithm used in this laboratory to measure dielectric properties assumes that all losses are contained in the $\varepsilon^{\prime \prime}$ term. Upon observing how the two loss terms appear in Maxwell's equations, one can choose to use them interchangeably through the relationship (in MKS units), 


$$
\sigma=\varepsilon^{\prime \prime} \varepsilon_{0} \omega
$$

where the units of conductivity are mhos/meter (or siemens/meter) and $\varepsilon_{0}$ is the permittivity of free space $\left(8.85 \times 10^{-12}\right.$ farads/meter $)$.

Squaring the expression for the complex propagation constant, substituting the expression for the square of the complex index of refraction, and equating real and imaginary components, one obtains two algebraic equations that relate the amplitude attenuation factor and phase constant to the complex dielectric constant:

$$
\beta^{2}-\alpha^{2}=\frac{\omega^{2}}{c^{2}} \varepsilon^{\prime}
$$

and

$$
\alpha \beta=\frac{\omega^{2} \varepsilon^{\prime \prime}}{2 c^{2}}
$$

Solving these equations for the amplitude attenuation factor and for the phase constant results in the following expressions: ${ }^{1}$

$$
\alpha=\frac{\omega}{c}\left[\frac{\varepsilon^{\prime}}{2}\left(\sqrt{1+\left(\frac{\varepsilon^{\prime \prime}}{\varepsilon^{\prime}}\right)^{2}}-1\right)\right]^{\frac{1}{2}}
$$

and

$$
\beta=\frac{\omega}{c}\left[\frac{\varepsilon^{\prime}}{2}\left(\sqrt{1+\left(\frac{\varepsilon^{\prime \prime}}{\varepsilon^{\prime}}\right)^{2}}+1\right)\right]^{\frac{1}{2}}
$$

\footnotetext{
${ }^{1}$ Had magnetic permeability been included, then the phase constant would have been:

$\beta^{2}=\frac{\omega^{2}}{2 c^{2}}\left[\left(\varepsilon^{\prime} \mu^{\prime}-\varepsilon^{\prime \prime} \mu^{\prime \prime}\right) \pm \sqrt{\left(\varepsilon^{\prime} \mu^{\prime}\right)^{2}+\left(\varepsilon^{\prime} \mu^{\prime \prime}\right)^{2}+\left(\varepsilon^{\prime \prime} \mu^{\prime}\right)^{2}+\left(\varepsilon^{\prime \prime} \mu^{\prime \prime}\right)^{2}}\right]$
}

and the attenuation coefficient would have been:

$\alpha=\frac{\omega^{2}\left(\varepsilon^{\prime} \mu^{\prime \prime}+\varepsilon^{\prime \prime} \mu^{\prime}\right)}{2 \beta c^{2}}$ 
The $\varepsilon^{\prime \prime} / \varepsilon^{\prime}$ ratio is also referred to as the loss tangent. Keep in mind that some researchers prefer to work with the electrical conductivity in place of the dielectric loss term, so that the radicand might look different in other references (e.g., $\varepsilon^{\prime \prime} / \varepsilon^{\prime}$ may be replaced by $\sigma /\left(\varepsilon^{\prime} \varepsilon_{0} \omega\right)$ ).

Plane waves of constant phase will propagate with a velocity

$$
v=\frac{\omega}{\beta}=c\left[\frac{\varepsilon^{\prime}}{2}\left(\sqrt{1+\left(\frac{\varepsilon^{\prime \prime}}{\varepsilon^{\prime}}\right)^{2}}+1\right)\right]^{-\frac{1}{2}}
$$

This phase velocity is not necessarily the speed with which the energy of the wave propagates through the medium. The latter is referred to as the group velocity and can be calculated as the rate of change of radial frequency with respect to the phase constant. However, as long as the phase velocity is relatively constant over the range of frequencies of interest, then there is little difference between phase velocity and group velocity.

The power intensity of the plane electromagnetic wave decreases exponentially with depth of penetration by the factor, $\mathrm{e}^{-2 \alpha x}$, or, in one unit of distance traveled, a decrease of $\mathrm{e}^{-2 \alpha}$. Power attenuation expressed in decibels per meter can then be written as:

$$
\text { power loss }=-8.6859 \frac{\omega}{c}\left[\frac{\varepsilon^{\prime}}{2}\left(\sqrt{1+\left(\frac{\varepsilon^{\prime \prime}}{\varepsilon^{\prime}}\right)^{2}}-1\right)\right]^{\frac{1}{2}}
$$




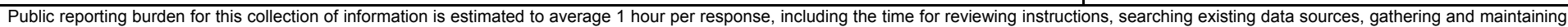

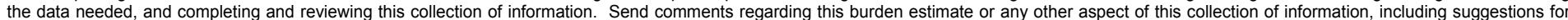

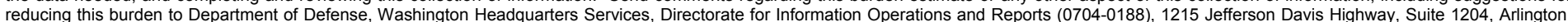

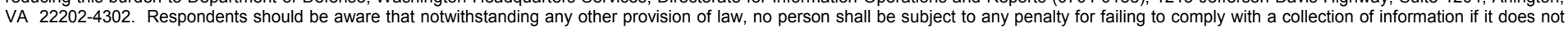
display a currently valid OMB control number. PLEASE DO NOT RETURN YOUR FORM TO THE ABOVE ADDRESS.
1. REPORT DATE (DD-MM-YYYY)
August 2005
Final report

\section{TITLE AND SUBTITLE}

Electromagnetic Power Attenuation in Soils

\section{DATES COVERED (From - To)}

5a. CONTRACT NUMBER

5b. GRANT NUMBER

5c. PROGRAM ELEMENT NUMBER

5d. PROJECT NUMBER

5e. TASK NUMBER

5f. WORK UNIT NUMBER

8. PERFORMING ORGANIZATION REPORT NUMBER

ERDC/EL TR-05-5

U.S. Army Engineer Research and Development Center

Environmental Laboratory

3909 Halls Ferry Road

Vicksburg, MS 39180-6199

9. SPONSORING / MONITORING AGENCY NAME(S) AND ADDRESS(ES)

U.S. Army Corps of Engineers

Washington, DC 20314-1000
10. SPONSOR/MONITOR'S ACRONYM(S)

11. SPONSOR/MONITOR'S REPORT NUMBER(S)

\section{DISTRIBUTION / AVAILABILITY STATEMENT}

Approved for public release; distribution is unlimited.

\section{SUPPLEMENTARY NOTES}

\section{ABSTRACT}

This study explores the possibility of predicting the attenuation of electromagnetic energy in soils as a function of soil type, soil moisture content, and the frequency of the sensor system being used to probe the soils. Of primary concern is the issue of safety; one does not want to risk an explosion when using high-power electromagnetic sensors to search for buried unexploded ordnance. While explicit predictive models could not be found because of the unpredictable effects of soil chemistry, simple statistical analyses did provide conservative guidance at fixed frequencies and selected soil moisture contents.

\section{SUBJECT TERMS}

Dielectric properties of soils

Electromagnetic sensors

\section{SECURITY CLASSIFICATION OF:}

\begin{tabular}{|l|l|l|}
\hline a. REPORT & b. ABSTRACT & c. THIS PAGE \\
UNCLASSIFIED & UNCLASSIFIED & UNCLASSIFIED \\
\hline
\end{tabular}

Power attenuation
17. LIMITATION OF ABSTRACT
18. NUMBER OF PAGES

48 19a. NAME OF RESPONSIBLE PERSON

19b. TELEPHONE NUMBER (include area code) 